\title{
Fusion Safety Program Annual Report Fiscal Year 1992
}

Douglas F. Holland Lee C. Cadwallader

J. Stephen Herring Glen R. Longhurst Kathy A. McCarthy Brad J. MerrllI

Steven J. Plet

Publlshed January 1993

Idaho National Engineering Laboratory EG\&G Idaho, Inc. Idaho Falls, Idaho 83415

Prepared for the U.S. Department of Energy Office of Energy Research Under DOE Idaho Fleld Office Contract DE-AC07-76ID01570 


\begin{abstract}
This report summarizes the major activities of the Fusion Safety Program in fiscal year 1992. The Idaho National Engineering Laboratory (INEL) is the designated lead laboratory and EG\&G Idaho, Inc. is the prime contractor for this program. The Fusion Safety Program was initiated in 1979. Activities are conducted at the INEL and in participating organizations including the Westinghouse Hanford Company at the Hanford Engineering Development Laboratory, the Massachusetts Institute of Technology, and the University of Wisconsin. The technical areas covered in the report include tritium safety, activation product release, reactions involving beryllium, reactions involving lithium breeding materials, safety of fusion magnet systems, plasma disruptions, risk assessment failure rate data base, and computer code development for reactor transients. Also included in the report is a summary of the safety and environmental studies performed by the INEL for the Tokamak Physics Experiments and the Tokamak Fusion Test Reactor, the safety analysis for the International Thermonuclear Experimental Reactor design, and the technical support for the ARIES commercial reactor design study.
\end{abstract}




\section{CONTENTS}

ABSTRACT $\ldots \ldots \ldots \ldots \ldots \ldots \ldots \ldots \ldots \ldots \ldots \ldots \ldots \ldots \ldots \ldots \ldots \ldots \ldots$

INTRODUCTION $\ldots \ldots \ldots \ldots \ldots \ldots \ldots \ldots \ldots \ldots \ldots \ldots \ldots \ldots \ldots \ldots \ldots \ldots$

TRITIUM SAFETY $\ldots \ldots \ldots \ldots \ldots \ldots \ldots \ldots \ldots \ldots \ldots \ldots \ldots \ldots \ldots \ldots$

Major Accomplishments $\ldots \ldots \ldots \ldots \ldots \ldots \ldots \ldots \ldots \ldots \ldots \ldots \ldots \ldots \ldots \ldots$

Transport and Trapping in Beryllium $\ldots \ldots \ldots \ldots \ldots \ldots \ldots \ldots \ldots \ldots \ldots$

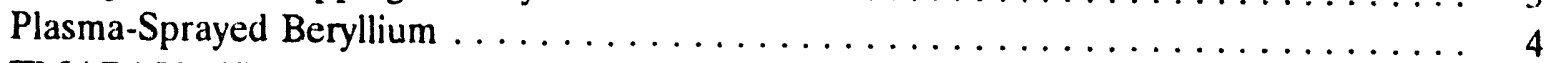

TMAP4 Verification and Validation $\ldots \ldots \ldots \ldots \ldots \ldots \ldots \ldots \ldots \ldots \ldots$

Fuel Burn Fraction and Tritium Inventory $\ldots \ldots \ldots \ldots \ldots \ldots \ldots \ldots \ldots$

Inertial Confinement Fusion $\ldots \ldots \ldots \ldots \ldots \ldots \ldots \ldots \ldots \ldots \ldots \ldots$

Future Activities $\ldots \ldots \ldots \ldots \ldots \ldots \ldots \ldots \ldots \ldots \ldots \ldots \ldots \ldots$

References $\ldots \ldots \ldots \ldots \ldots \ldots \ldots \ldots \ldots \ldots \ldots \ldots \ldots \ldots \ldots \ldots \ldots \ldots$

BERYLLIUM SAFETY $\ldots \ldots \ldots \ldots \ldots \ldots \ldots \ldots \ldots \ldots \ldots \ldots \ldots \ldots$

Major Accomplishments $\ldots \ldots \ldots \ldots \ldots \ldots \ldots \ldots \ldots \ldots \ldots \ldots \ldots \ldots$

Beryllium Technology Workshop $\ldots \ldots \ldots \ldots \ldots \ldots \ldots \ldots \ldots \ldots \ldots \ldots$

Mechanical Testing of Beryllium $\ldots \ldots \ldots \ldots \ldots \ldots \ldots \ldots \ldots \ldots \ldots \ldots \ldots$

Future Activities $\ldots \ldots \ldots \ldots \ldots \ldots \ldots \ldots \ldots \ldots \ldots \ldots \ldots \ldots$

References $\ldots \ldots \ldots \ldots \ldots \ldots \ldots \ldots \ldots \ldots \ldots \ldots \ldots \ldots \ldots \ldots \ldots \ldots \ldots$

ACTIVATION PRODUCT CHEMICAL REACTIVITY, VOLATILITY, AND

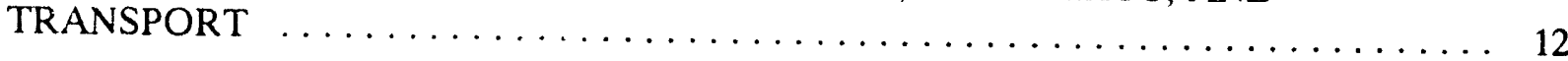

Major Accomplishments $\ldots \ldots \ldots \ldots \ldots \ldots \ldots \ldots \ldots \ldots \ldots \ldots \ldots \ldots$

Volatility and Chemical Reactivity Tests of Plasma-Sprayed Beryllium and Tungsten . . 12

Tests of the Reaction Rates and Volatility of Nisbium with Air and Steam . . . . . . . 13

Exploratory Study of Burn Time, Duty Factor, and Fluence on ITER Activation Hazards 15

Exploratory Transport Tests $\ldots \ldots \ldots \ldots \ldots \ldots \ldots \ldots \ldots \ldots \ldots \ldots \ldots \ldots \ldots$

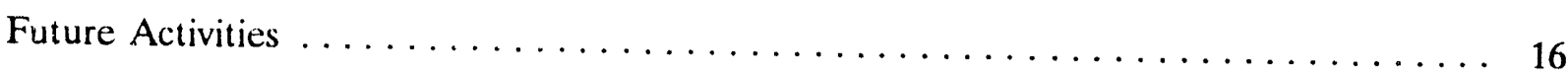

References $\ldots \ldots \ldots \ldots \ldots \ldots \ldots \ldots \ldots \ldots \ldots \ldots \ldots \ldots \ldots \ldots \ldots \ldots$

LIQUID METAL CHEMICAL REACTIONS $\ldots \ldots \ldots \ldots \ldots \ldots \ldots \ldots \ldots \ldots \ldots$ 
Major Accomplishments $\ldots \ldots \ldots \ldots \ldots \ldots \ldots \ldots \ldots \ldots \ldots \ldots \ldots \ldots$

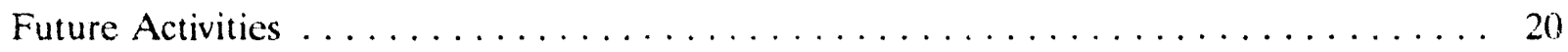

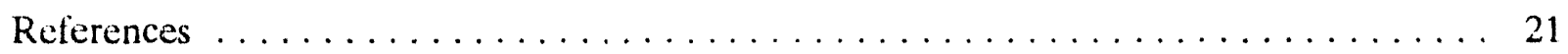

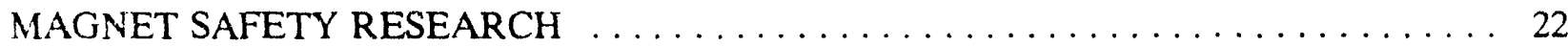

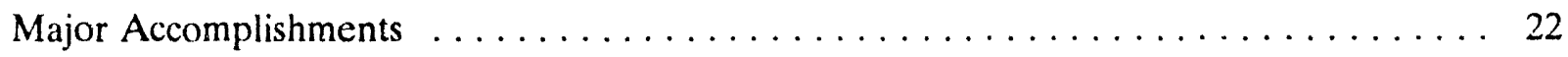

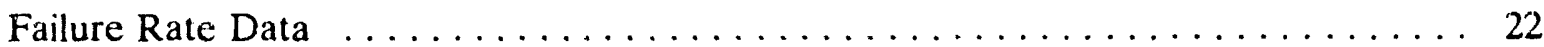

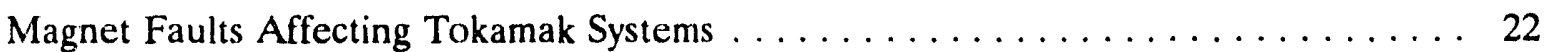

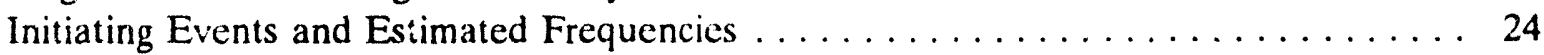

Internally-Cooled Conduit Superconductor Quench Code Development . . . . . . . . 24

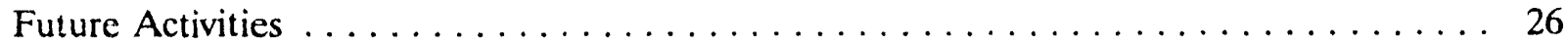

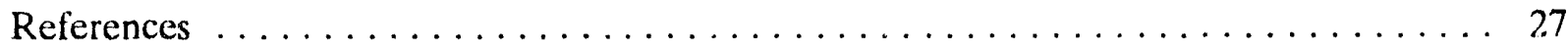

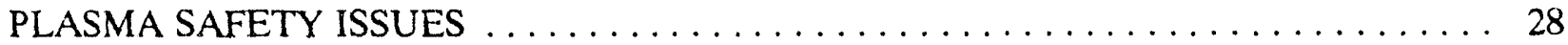

Major Accomplishments $\ldots \ldots \ldots \ldots \ldots \ldots \ldots \ldots \ldots \ldots \ldots \ldots \ldots \ldots$

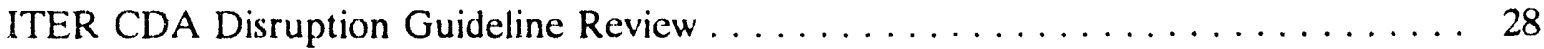

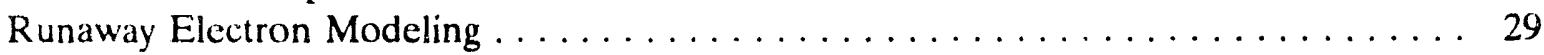

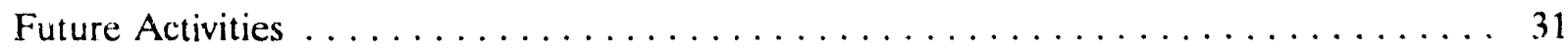

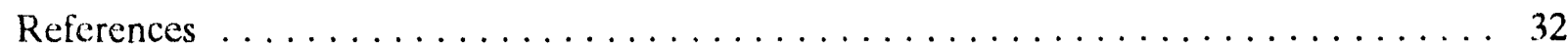

RISK ASSESSMENT $\ldots \ldots \ldots \ldots \ldots \ldots \ldots \ldots \ldots \ldots \ldots \ldots \ldots \ldots$

Major Accomplishments $\ldots \ldots \ldots \ldots \ldots \ldots \ldots \ldots \ldots \ldots \ldots \ldots \ldots \ldots \ldots \ldots$

Scaling Component Failure Rates $\ldots \ldots \ldots \ldots \ldots \ldots \ldots \ldots \ldots \ldots \ldots \ldots \ldots \ldots$

Dose Consequence Computer Codes $\ldots \ldots \ldots \ldots \ldots \ldots \ldots \ldots \ldots \ldots \ldots \ldots \ldots$

Future Activities $\ldots \ldots \ldots \ldots \ldots \ldots \ldots \ldots \ldots \ldots \ldots \ldots \ldots \ldots$

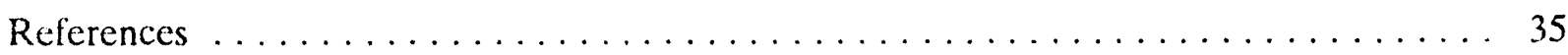

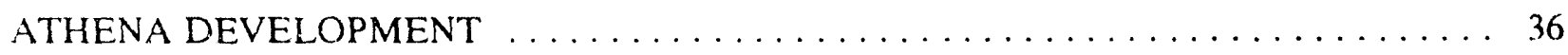

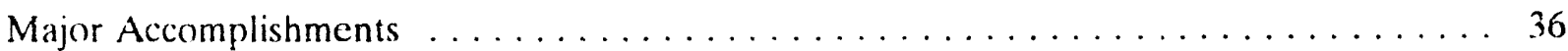

Future Activities $\ldots \ldots \ldots \ldots \ldots \ldots \ldots \ldots \ldots \ldots \ldots \ldots \ldots$ 
SAFETY AND ENVIRONMENTAL STUDIES FOR THE TOKAMAK PHYSICS

EXPERIMENT $\ldots \ldots \ldots \ldots \ldots \ldots \ldots \ldots \ldots \ldots \ldots \ldots \ldots \ldots \ldots \ldots \ldots \ldots$

Major Accomplishments $\ldots \ldots \ldots \ldots \ldots \ldots \ldots \ldots \ldots \ldots \ldots \ldots \ldots \ldots \ldots$

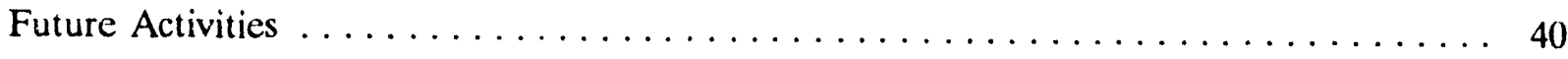

References $\ldots \ldots \ldots \ldots \ldots \ldots \ldots \ldots \ldots \ldots \ldots \ldots \ldots \ldots \ldots \ldots \ldots \ldots$

ARIES TOKAMAK REACTOR DESIGN STUDY $\ldots \ldots \ldots \ldots \ldots \ldots \ldots \ldots \ldots$

Major Accomplishments $\ldots \ldots \ldots \ldots \ldots \ldots \ldots \ldots \ldots \ldots \ldots \ldots \ldots \ldots \ldots \ldots$

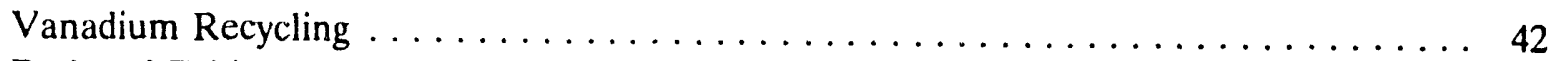

Reduced Tritium Pumping System $\ldots \ldots \ldots \ldots \ldots \ldots \ldots \ldots \ldots \ldots \ldots \ldots$

Future Activities $\ldots \ldots \ldots \ldots \ldots \ldots \ldots \ldots \ldots \ldots \ldots \ldots \ldots \ldots \ldots \ldots$

References $\ldots \ldots \ldots \ldots \ldots \ldots \ldots \ldots \ldots \ldots \ldots \ldots \ldots \ldots \ldots \ldots \ldots \ldots$

INTERNATIONAL THERMONUCLEAR EXPERIMENTAL REACTOR

PARTICIPATION $\ldots \ldots \ldots \ldots \ldots \ldots \ldots \ldots \ldots \ldots \ldots \ldots \ldots \ldots \ldots \ldots \ldots$

Major Accomplishments $\ldots \ldots \ldots \ldots \ldots \ldots \ldots \ldots \ldots \ldots \ldots \ldots \ldots \ldots \ldots$

Implementing U.S. Consensus ITER Safety Approach $\ldots \ldots \ldots \ldots \ldots \ldots \ldots \ldots$

Building International Consensus on ITER Safety Approach $\ldots \ldots \ldots \ldots \ldots \ldots \ldots \ldots$

Safety Assessment of CDA to EDA Changes . . . . . . . . . . . . . . . . 50

Development of an ITER EDA Safety and Environmental Research and Design Plan . 50

Initiation of the Process Leading to U.S. Regulatory Approval . . . . . . . . . . 51

Future Activities $\ldots \ldots \ldots \ldots \ldots \ldots \ldots \ldots \ldots \ldots \ldots \ldots \ldots \ldots \ldots$

References $\ldots \ldots \ldots \ldots \ldots \ldots \ldots \ldots \ldots \ldots \ldots \ldots \ldots \ldots \ldots \ldots \ldots \ldots$

APPENDIX A-ABSTRACTS OR SUMMARIES OF FUSION SAFETY PROGRAM

PUBLICATIONS

Tritium Safety $\ldots \ldots \ldots \ldots \ldots \ldots \ldots \ldots \ldots \ldots \ldots \ldots \ldots \ldots \ldots \ldots \ldots$

Beryllium Safety $\ldots \ldots \ldots \ldots \ldots \ldots \ldots \ldots \ldots \ldots \ldots \ldots \ldots \ldots \ldots \ldots$

Activation Product Chemical Reactivity, Volatility, and Transport .......... A-6

Liquid Metal Chemical Reactions $\ldots \ldots \ldots \ldots \ldots \ldots \ldots \ldots \ldots \ldots \ldots \ldots \ldots$ 
Magnet Safety Research

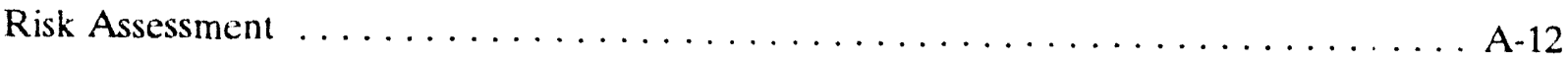

ATHENA Development $\ldots \ldots \ldots \ldots \ldots \ldots \ldots \ldots \ldots \ldots \ldots \ldots \ldots \ldots \ldots$

Safety and Environmental Studies for the Tokamak Physics Experiment $\ldots \ldots \ldots \ldots$ A-16

\section{FIGURES}

1. Surface modification evident in beryllium foils after implantation to a fluence of $2.3 \times 10^{24} \mathrm{D} / \mathrm{m}^{2}$ at $500 \mathrm{eV} / \mathrm{amu}$ and $753 \mathrm{~K}$

2. Tritium burn fraction as a function of fuel recycle fraction $\ldots \ldots \ldots \ldots \ldots \ldots$

3. Tritium ash fraction as a function of fuel recycle fraction $\ldots \ldots \ldots \ldots \ldots$

4. Reaction rates of various forms of beryllium in a steam environment $\ldots \ldots \ldots \ldots$

5. Hydrogen generation rates for several candidate plasma-facing materials $\ldots \ldots \ldots \ldots$

6. Maximum mobilized dose for niobium and copper in air and steam $\ldots \ldots \ldots \ldots$

7. The effect of isotope halflife, burn time, duty factor, and fluence on inventory ratio ... 16

8. Pressure in a typical $\mathrm{Ga} /$ water test $\left(\mathrm{Ga}\right.$ at $\left.600^{\circ} \mathrm{C}\right) \ldots \ldots \ldots \ldots \ldots \ldots$

9. Predicted plasma and runaway electron current for TFTR disruptive shot $19964 \ldots \ldots$. . 30

10. Runaway electron drift orbits $\ldots \ldots \ldots \ldots \ldots \ldots \ldots \ldots \ldots \ldots \ldots \ldots \ldots \ldots \ldots$

11. Collecting and applying failure rate data for fusion usage $\ldots \ldots \ldots \ldots \ldots \ldots$

12. Comparison of ATHENA calculations using the Forslund correlation and interphase heat transfer with an enhancement factor of twelve $\ldots \ldots \ldots \ldots \ldots \ldots \ldots \ldots \ldots \ldots$

13. Snail pump schematic $\ldots \ldots \ldots \ldots \ldots \ldots \ldots \ldots \ldots \ldots \ldots \ldots \ldots \ldots$

14. Cost-effective approach to solving fusion safety issues $\ldots \ldots \ldots \ldots \ldots \ldots \ldots$

15. Distinction between technically-driven and regulatory-driven safety processes $\ldots \ldots \ldots 53$ 


\section{TABLES}

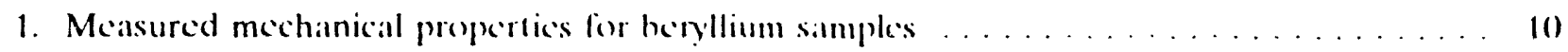

2. Fault interaction matrix for off-normal operation of ITER systems $\ldots \ldots \ldots \ldots$

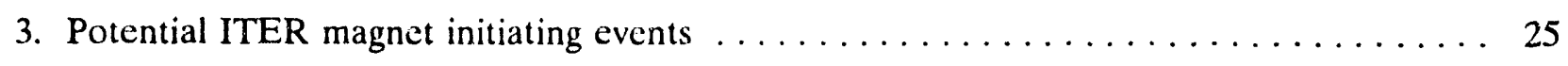

4. Comparison of the four ARIES designs $\ldots \ldots \ldots \ldots \ldots \ldots \ldots \ldots \ldots \ldots$

5. Summary of potential ITER changes and impacts on safety performance $\ldots \ldots \ldots \ldots 1$ 


\section{FUSION SAFETY PROGRAM ANNUAL REPORT FISCAL YEAR 1992}

\section{INTRODUCTION}

Fusion power has the potential to be an important energy source while remaining inherently safe with attractive environmental features. To make this potential a reality requires identifying safety and environmental concerns early and then developing the materials and technology needed to meet these concerns.

In 1979, the U.S. Department of Eriergy established the Fusion Safety I'ogram (FSP) to support safety in fusion development. The Idaho National Engineering Labrsratory (INEL) is the designated lead laboratcry and EG\&G Idaho, Inc., is the prime contractor for this program. The program focus is to develop safety and environmental goals for fusion energy production, identify potential safety and environmental concerns in fusion devices and approaches to resolve these concerns, and develop the risk assessment methorlologies and safety-analysis computer codes required to verify that fusion reactors are safe and environmentally attractive.

Realization of fusion's potential will result from advances in plasma physics and technology that enhance safety and environmental attractiveness. Plasma physicists must address issues of plasma disruptions, run-away electrons, emergency plasma shutdown, control of power levels, and reduction of tritium throughput. Priorities in the technology area include developing plasma-facing components and breeding blankets that are low in activation products and tritium and are free of chemical reactions producing explosive quantities of hydrogen. Ultimately, low activation materials will need to be developed for all components and structures exposed to fusion neutrons. The FSP sets a high emphasis on providing technical support and guidance in these critical areas.

International cooperation has become an iricreasingly important part of the FSP at the iNEL. In addition to cooperating with Japan, the European Community, and the Russian Federation in the International Thermonuclear Experimental Reactor (ITER) design, an agreement for cooperation under the International Energy Agency is now in place. Bilateral cooperation has greatly enhanced the fusion safety work. In fiscal year 1992, joint work was completed with Canada and the United Kingdom.

Activities performed during this fiscal year include conducting experimental tests to develop data needed for safety analysis, developing computer codes and methodology for safety analysis, and participating in studies that support safety in fusion development. Because the safety tests and analyses performed in support of commercial reactors also apply to near-term fusion devices, the FSP was involved in safety support for the Tokamak Physics Experiment (TPX) and the Tokamak Fusion Test Reactor (TFTR) directed by the Princeton Plasma Physics Laboratory. Additionally, the FSP participated in the ITER design effort and led the U.S. safety analysis participation. The new commercial reactor design study, ARIES, was continued with FSP participation in the safety area.

The following sections summarize work completed under each of these activities by the INEL and participating organizations, including the Westinghouse Hanford Company at the 
Hanford Engineering Development Laboratory, the Massachusetts Institute of Technology, and the University of Wisconsin.

Broader ITER design studies and program- matic activities appear in the ITER scction More specific ITER work appears under the appropriate technical area. Appendix A contains abstracts of publications based on work completed in fiscal year 1992. 


\section{TRITIUM SAFETY}

\section{Researchers: R. A. Anderl, T. J. Dolan, M. R. Hankins, D. F. Holland, G. R. Longhurst, B. J. Merrill, and R. J. Pawelko, INEL}

We can make fusion reactor designs safer by minimizing the inventories of tritium in the reactor and associated systems or by taking steps to reduce routine and accidental effluents. The Fusion Safety Program is pursuing tritiumrelated safety concerns in a program of research and study. This year our focus has been modeling and experimenting with plasma-driven permeation of hydrogen isotopes through structural materials, especially beryllium. Our purpose is to increase understanding of the mechanisms and processes that are significant to accidents and normal operational release of tritium in fusion reactors.

\section{Major Accomplishments}

Transport and Trapping in Beryllium. We have conducted preliminary experiments to evaluate hydrogen transport and trapping characteristics in beryllium. ${ }^{1}$ Beryllium is a prime candidate for plasma-facing material for the International Thermonuclear Experimental Reactor (ITER). We conducted implantation driven permeation experiments using a massanalyzed, 3-keV $\mathrm{D}_{3}{ }^{+}$ion beam in a permeation system. $^{23}$ Beam flux densities through a $20-\mathrm{mm}^{2}$ aperture were $5 \times 10^{19}$ to $6 \times 10^{19} \mathrm{D} / \mathrm{m}^{2}$-s on target. Re-emission and permeation data were derived from a quadrupole mass spectrometer's mass 4 signals $\left(D_{2}\right)$. Beryllium specimens used were $25-\mathrm{mm}$ diameter disks of high purity foil with thicknesses ranging from $25 \mu \mathrm{m}$ to $71 \mu \mathrm{m}$. Two types of $\mathrm{Be}$ were investigated: (a) BrushWellman Type PF-60, a hot-rolled, hot-pressed powder metallurgy product with a purity of 99.6 at\% Be, and (b) Electrofusion type IF-1 foil, an extruded, hot-rolled product cast from vacuum-melted, electrolytically-refined $\mathrm{Be}$ flakes, with 99.96 at\% Be. We tested PF-60 material with as-received surface conditions and foils of both types mechanically polished to a mirror finish. After implantation testing, R. G. Macaulay-Newcombe at McMaster University performed nuclear reaction analysis using an $800-\mathrm{keV}{ }^{3} \mathrm{He}^{+}$incident beam and the ${ }^{3} \mathrm{He}(\mathrm{d}, \mathrm{p}){ }^{4} \mathrm{He}$ reaction to probe for deuterium to a depth of $\approx 0.55 \mu \mathrm{m}$ at the upstream surface of the sample. ${ }^{1}$

Our permeation data showed several general features. First, we saw no $\mathrm{p}^{\wedge}$ rmeation at sample temperatures below $750 \mathrm{~K}$. Next, for tests where permeation was observed, the breakthrough time was about four orders of magnitude longer than expected, suggesting the influence of hydrogen trapping. Finally, we saw less than $10^{-5}$ of the implantation flux permeating the foils. That indicates the possible influence of surface effects and/or a diffusive permeation barrier.

Scanning electron microscope measurements in the implanted region indicated a significant change both in topography and porosity of the upstream surface. The region exhibited numerous cavities $(\leq 1 \mu \mathrm{m}$ in diameter), apparently caused by the agglomeration of microscopic bubbles with formation of voids that were uncovered by sputter erosion of the surface. In contrast, regions outside the beam spot and on the back side manifested the textured surface typical for the "as-received" surface oxide condition. One of the modified surface zones is shown in Figure 1. The bottom photomicrograph in that figure shows a broken edge where it is evident that the cavities are much deeper than the 16-nm implantation depth. 

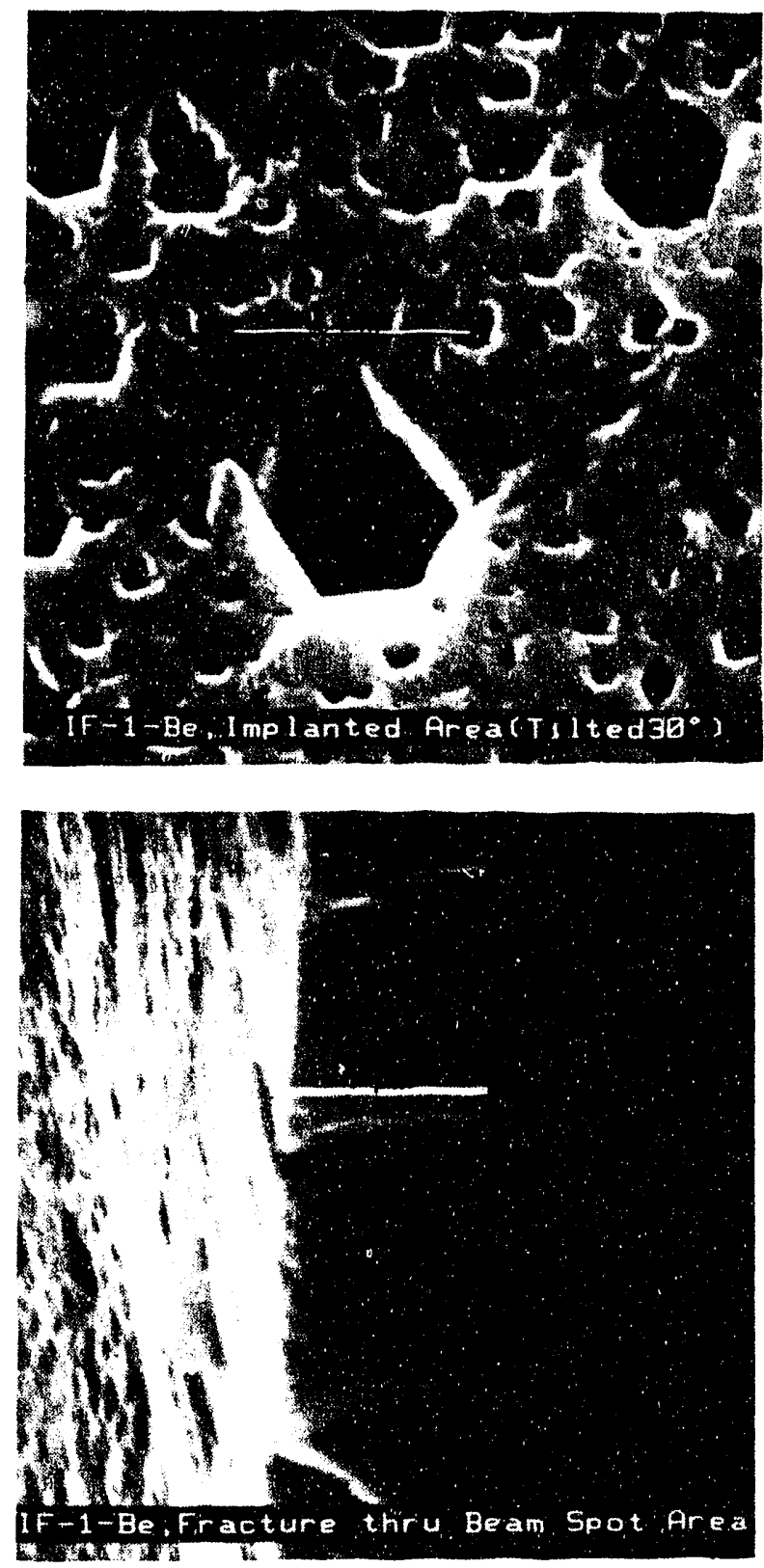

Figure 1. Surface modification evident in beryllium foils after implantation to a fluence of $2.3 \times 10^{24} \mathrm{D} / \mathrm{m}^{2}$ at $500 \mathrm{eV} / \mathrm{amu}$ and $753 \mathrm{~K}$.

The permeation data were not sufticient to ascertain whether the effective diffusivity regime or the strong-trapping regime ${ }^{4,5}$ dominates, or whether bulk trapping or modifiedlayer effects are mainly responsible for permeation delays. Nuclear reaction analyses indicate that the retained deuterium concentration reached a maximum of about 0.1 at $\%$ at a depth of about $0.2-0.4 \mu \mathrm{m}$.
These findings may have important implications for plasma-facing components in fusion reactor applications where material modification, similar to that observed in these experiments, takes place. Surface modification like that in Figure 1 is not expected for ion energies well below $100 \mathrm{eV}$. However, if it does occur and trapping in the modified region dominates, then several observations may be made. The breakthrough time for permeation through beryllium structures a few millimeters thick may be relatively independent of material thickness. There may be substantially more tritium in the structurally-modified layer at the plasma face than in the bulk material, even when considering thicknesses of several millimeters for the beryllium plasma-facing component. Finally, the magnitude of permeation expected may be significantly reduced because of enhanced re-emission at the modified, plasma-facing surface. The additional reduction in permeating fraction caused by the oxide film in our experiments may be absent or of reduced effect in composite-material applications. Additional experiments are planned to further clarify these issues.

Plasma-Sprayed Beryllium. As part of our work to evaluate tritium retention and permeation in potential plasma-facing components for ITER, we have conducted an experiment to evaluate these characteristics in a sample of plasma-arc sprayed beryllium. This material was fabricated by Battelle Columbus Laboratory as part of the same lot delivered to Sandia National Laboratory, Albuquerque for mechanical property tests. The basic finding was that the material was sufficiently porous so that $0.17 \%$ of the deuterium molecules falling on the "upstream" surface from residual gas pressure were permeating through the sample, which was nominally $0.1 \mathrm{~mm}$ thick. Also, $0.12 \%$ of the deuterium atoms implanted in the surface by the ion beam permeated through to the downstream side with virtually no delay. This probably occurred by short-path diffusion of deuterium atoms to a pore where recombi- 
nation took place followed by molecular diffusion to both upstream and downstream faces. For comparison, similar tests on fully dense hot-rolled, vacuum-melted or sinteredpowder high purity beryllium of about the same thickness resulted in only $0.001 \%$ of implanted atoms permeating after a delay of several hours, and none of the molecular gas appeared to permeate.

TMAP4 Verification and Validation. The Tritium Migration Analysis Program (TMAP4) code developed at the INEL has been verified and validated to Quality Level A. ${ }^{6}$ Also, a ncW user's manual has been prepared. ${ }^{7}$ This code is now ready for use in safety analyses involving plasma-facing or other structures and enclosures where tritium permeation is an issue.

Fuel Burn Fraction and Tritium Inventory. For ITER to demonstrate the attractive safety and environmental potential of fusion, the tritium inventories need to be reduced from the ITER Conceptual Design Activity (CDA) values. Lower tritium inventories would also make the regulatory approval process easier. A goal of $1000 \mathrm{~g}-\mathrm{T}$ was suggested by P. Rebut. Since some inventories will be in the plasmafacing components (PFCs) and in the blanket, the total tritium in the vacuum pumping and tritium processing systems will need to be limited to about $500 \mathrm{~g}-\mathrm{T}$ to meet Rebut's goal. Meeting this limit will be challenging unless the tritium processing system flows can be reduced.

The relationship between tritium inventory and flow can be roughly determined from the CDA. For the CDA, the tritium flow was about $210 \mathrm{~g}-\mathrm{T} / \mathrm{hr}$, and the inventory in the vacuum pumps, processing systems, and storage was about $2,600 \mathrm{~g}-\mathrm{T}$. The design was conservative, and attention to inventory reduction could certainly reduce this value by a factor of two (i.e., to $1,300 \mathrm{~g}-\mathrm{T}$ ). Because tritium flow is inversely proportional to tritium burnup, the CDA tritium burn fraction (about 0.03 ) will need to be increased by about a factor of two to meet the desired $500 \mathrm{~g}$-T limit.

Tritium burn fraction can be increased by increasing either fuel recycle, plasma density, plasma temperature, particle confinement time, or deuterium fraction. However, these parameters are interrelated, and changes to them greatly affect the operating point for the machine. To investigate burn fraction in a more detailed way, we developed a zerodimensional model based on the physics relationships. $^{8} \quad$ This model calculates equilibrium plasma power conditions using the Rebut-Lallia L-mode energy confinement scaling expression, given various machine characteristics (such as plasma current, temperature, beta, major radius, minor radius, anci alongation).

We examined three cases with our model: an ash recycle equal to that of the fuel, one-half that of the fuel, and no ash recycle. These cases correspond to a system that would recycle the plasma exhaust and either provide no ash removal, $50 \%$ ash removal, or $100 \%$ ash removal, respectively. Figures 2 and 3 contain the results of tritium burn and ash fraction calculations for these cases, respectively. The burn fractions were similar between the cases; however, the ash fractions were very different. The ash had a dramatic effect on plasma fusion power. For $100 \%$ ash recycle, the power decreased significantly when the fuel recycle fraction exceeded 0.5 . If a recycle system existed that could remove $100 \%$ of the ash before recycling the unburned fuel, the fuel supply rate could be reduced from $117 \mathrm{~g}-\mathrm{T} / \mathrm{hr}$ to $6 \mathrm{~g}-\mathrm{T} / \mathrm{hr}$. However, an encouraging result was obtained for a recycle system that is only $50 \%$ efficient. For this case, the same reduction in fuel supply rate was achieved with only a $7 \%$ reduction in fusion power.

Inertial Confinement Fusion. We have been part of the conceptual design team for the High-Yield Lithium-Injection Fusion Energy 
(HYLIFE)-II inertial-confinement fusion reactor design." This year our task was to refine the design of the vacuum disengager used to remove tritium from the Flibe entering the heat exchanger system. Projected performance was good enough that the need for an intermediate hea: exchange loop has been eliminated, resulting in considerable savings.

\section{Future Activities}

Our plasma-driven permeation experiments will continue. These experiments will focus on evaluating the ways we can reduce permeation into the coolant stream by taking advantage of the transport and trapping properties for hydrogen isotopes in fully dense beryllium and in less than fully dense beryllium and tungsten. We also expect to investigate other materials such as SiC and V alloys. These experiments will be complementary to larger scale experiments planned for the Tritium Plasma Fincriment, which was moved to the Tritium

t ms Test Assembly at Los Alamos from jia Livermore Laboratory.

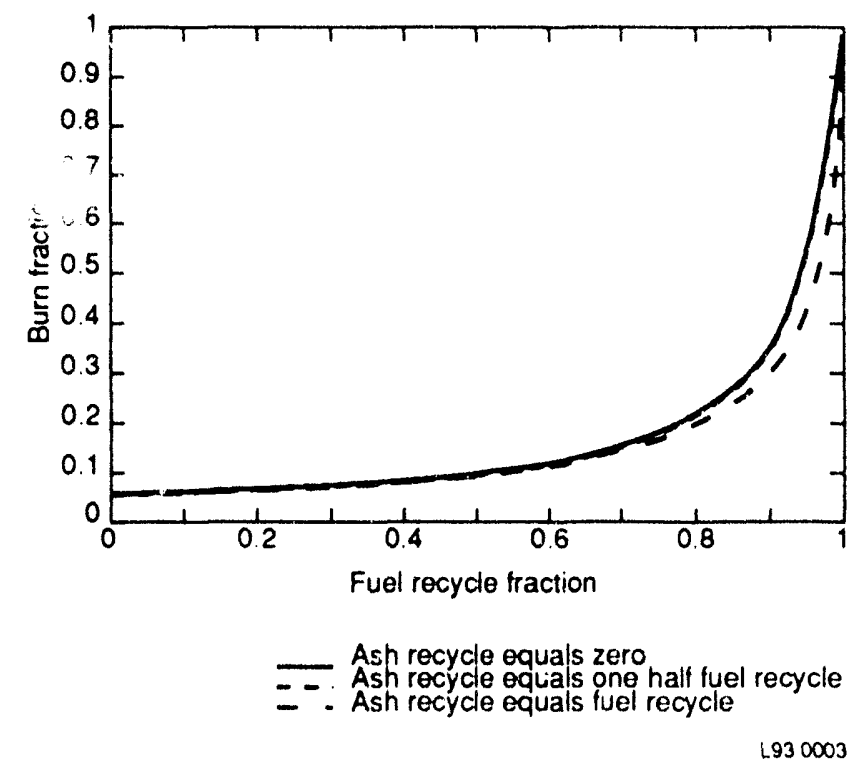

Figure 2. Tritium burn fraction as a function of fuel recycle fraction.

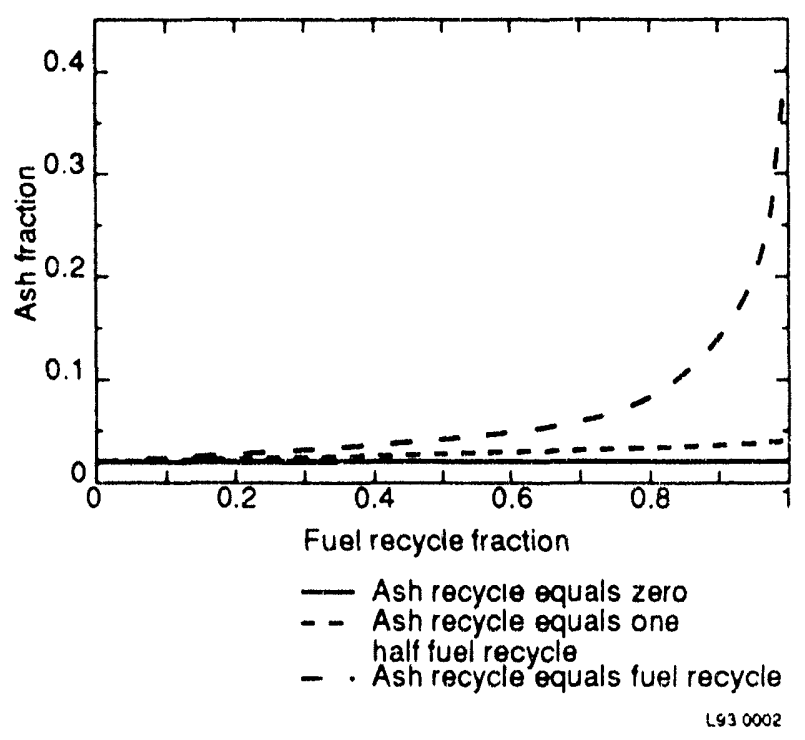

Figure 3. Tritium ash fraction as a function of fuel recycle fraction. 


\section{References}

1. R. A. Anderl, M. R. Hankins, G. R. Longhurst, R. J. Pawelko, and R. G. MacaulayNewcombe, "Hydrogen Transport Behavior of Beryllium," 10th International Conference on Plasma Surface Interactions in Controlled Fusion Devices, March 30-April 3, 1992, Monterey, California, also published in Journal of Nuclear Materials, 196-198, 1992, pp. 986-991.

2. D. F. Holland and R. A. Anderl, "Implantation-Driven Tritiuın Permeation in Vanadium Alloy Fusion Reactors," Fusion Technology, 14, September 1988, pp. 707-712.

3. R. A. Anderl, D. F. Holland, G. R. Longhurst, and D. A. Struttmann, "Permeation of Deuterium Implanted into Fusion Reactor Materials," Fusion Technology, 8, 1985, pp. 2299-2305.

4. G. R. Longhurst, Trapping Effects on Diffusion Transients, EGG-FSP-9789, July 1991.

5. R. A. Anderl et al., "Deuterium Transport and Trapping in Polycrystalline Tungsten," 4th Topical Meeting on Tritium in Fission, Fusion, and Isotopic Applications, Albuquerque, New Mexico, September 29-October 4, 1991, also published in Fusion Technology 21, 19. p. 745.

6. G. R. Longhurst, S. L. Harms, F. S. Marwil, and B. G. Miller, Verification and Validation of TMAP4, EGG-FSP-10347, July 8, 1992.

7. G. R. Longhurst, D. F. Holland, J. L. Jones, and B. J. Merrill, TMAP4 User's Manual, EGG-FSP-10315, June 12, 1992.

8. N. A. Uckan et al., ITER Physics Design Guidelines, ITER-TN-PH-9-7, March 1990.

9. R. W. Moir et al., HYLIFE-II Progress Report, UCID-21816, December 1991, Lawrence Livermore National Laboratory, Livermore, California. 


\section{BERYLLIUM SAFETY}

\section{Researchers: G. R. Longhurst and R. S. Wallace, INEL; S. P. Abeln, EG\&G Rocky Flats; J. M. Beeston, Consultant}

Beryllium is a prominent candidate for plasma-facing materia? in the International Thermonuclear Expe: mental Reactor (ITER). It was used in the Join reuropean Torus (JET), and it has potent upplicution as a neutron multiplier material in the breeding blanket of several fusion reactor designs. There are yet many unknowns regarding the response of beryllium to the fusion environment. Among them is the effect of neutron irradiation on the mechanical properties of strength ard ductility. A program was begun in 1988 that seeks to resolve some of those unknowns. That program involves manufacturing beryllium of various densities and irradiating samples in the Advanced Test Reactor (ATR) and in the Materials Open Test Assembly (MOTA) at the Fast Flux Test Facility (FFTF) at the Hanford, Washington site. Irradiated samples are then tested for strength and ductility, and the results compared with similar data for nonirradiated control samples.

\section{Major Accomplishments}

Beryllium Technology Workshop. In 1989, we held an international workshop at the INEL on beryllium research and technology that involved mainly researchers from the INEL, Sandia Livermore Laboratory, and Japanese participants. As a followup to that meeting, and to extend the participation to researchers in Europe and other nations, we organized a second beryllium technology workshop.' More than 40 specialists attended representing Canada, England, France, Germany, Japan, and the United States including designers and private consultants. Twelve presentations were made that collectively summarized work involving beryllium at the represented insti- tutions. Following these formal presentations, we had a group discussion of the areas where additional research was needed or planned and the relative importance of these areas to fusion.

Dimensional stability under irradiation was singled out as requiring the most urgent attention. It was followed in urgency by changes in the mechanical properties, notably ductility and creep resistance with neutron irradiation. Third in priority was a thorough understanding of tritium interactions with beryllium, particularly as influenced by neutron irradiation. Other issues were a good understanding of manufacturing capabilities, the functional integrity of varicus manufactured forms of beryllium, and requirements and capabilities for disposal, especially if beryllium has been rendered radioactive. Bonding of beryllium to other materials is another area requiring better understanding as are plasma interactions and erosion.

A report was published that includes copies of the presentations or supplementary written material. It also serves as a directory of workers who attended the meeting.'

Mechanical Testing of Beryllium. Beryllium samples irradiated in ATR were tested for strength and ductility in a special fixture assembled in the INEL Tritium Research Laboratory. ${ }^{2}$ Samples of $80 \%$ and $97 \%$ density had been irradiated to a neutron fluence of $2.6 \times 10^{25} \mathrm{n} / \mathrm{m}^{2}(\mathrm{E}>1 \mathrm{MeV})$ at an irradiation temperature of $75^{\circ} \mathrm{C}$. Linear swelling was measured on irradiated samples. These samples were compression tested at room temperature, and the results were compared with similar tests on unirradiated specimens. The unirradiated or 
control specimens were tested in both tension and compression. Splitting tensile tests (accomplished by compressive edge-loading of the cylindrical specimens) were substituted for standard tension tests on irradiated specimens because of the small sample sizes that could be accommodated in the reactor.

We found the irradiation increased the strength by approximately four times and reduced the ductility to approximately one fourth. Failure was generally ductile, but the $80 \%$ dense irradiated samples failed in brittle fracture with significant generation of fine particles and release of small quantities of tritium. Detailed data are listed in Table 1.

\section{Future Activities}

Our plans to conduct similar testing on the samples irradiated in the FFTF have been frustrated by the unavailability of funding needed to remove the samples from the lithium-filled titanium-zirconium-molybdenum (TZM) canisters in which they were irradiated. In the mean time, we are proceeding to prepare the test cell, the necessary furnace, and other equipment needed to test the samples at temperatures of $425-575^{\circ} \mathrm{C}$, consistent with the irradiation temperatures. We plan to conduct the testing on the FFTF samples as soon as they have been removed from their encapsulation and become available at the INEL.

We also pian to conduct additional workshops on beryllium research and technology. It seems prudent to organize these at least every two years, thus allowing a reasonable period for progress to be achieved between meetings. Other important beryllium safety issues we hope to pursue include beryllium disposal and waste management, recycling, and safe handling practices in the fusion environment. 
Table 1. Measured mechanical properties for beryllium samples.

\begin{tabular}{|c|c|c|c|c|c|c|c|}
\hline $\begin{array}{l}\text { Sample } \\
\text { density }\end{array}$ & Condition & $\begin{array}{c}\text { Linear } \\
\text { swelling } \\
\Delta \mathrm{L} / \mathrm{L}(\%)\end{array}$ & Test type & $\begin{array}{c}\text { Yield } \\
\text { strength } \\
(0.2 \%, \mathrm{MPa})\end{array}$ & $\begin{array}{c}\text { Ultimate } \\
\text { strength } \\
(\mathrm{MPa})\end{array}$ & $\begin{array}{c}\text { Ductility } \\
(\%)\end{array}$ & $\begin{array}{l}\text { Number } \\
\text { of tests }\end{array}$ \\
\hline \multirow[t]{2}{*}{$100 \%$} & Control & - & Tension & $245 \pm 10$ & $318 \pm 5$ & $0.6 \pm 0.05^{\mathrm{a}}$ & 4 \\
\hline & & - & Compression & $230 \pm 11$ & $458 \pm 44^{b}$ & 2.7 & 2 \\
\hline \multirow[t]{4}{*}{$97 \%$} & Control & - & Tension & $234 \pm 24$ & $302 \pm 12$ & $0.6 \pm 0.1^{a}$ & 4 \\
\hline & & - & Compression & $216 \pm 7$ & $310 \pm 10^{b}$ & 3.1 & 5 \\
\hline & Irradiated & $0.18 \pm 0.05$ & Splitting & $130 \pm 4$ & - & - & 2 \\
\hline & & & Compression & $928 \pm 4$ & $982 \pm 11$ & $0.6 \pm 0.05^{c}$ & 3 \\
\hline $86.6 \%$ & Control & - & Tension & $205 \pm 32$ & $245 \pm 42$ & $0.93 \pm 0.05^{\mathrm{a}}$ & 4 \\
\hline $85 \%$ & Control & - & Tension & $211 \pm 19$ & $240 \pm 20$ & $0.37 \pm 0.06^{\mathrm{a}}$ & 3 \\
\hline \multirow[t]{4}{*}{$80 \%$} & Control & - & Tension & $162 \pm 13$ & $167 \pm 14$ & $0.25 \pm 0.1^{\mathrm{a}}$ & 5 \\
\hline & & - & Compression & $140 \pm 3$ & $204 \pm 5^{b}$ & 1.74 & 5 \\
\hline & Irradiated & $0.18 \pm 0.04$ & Splitting & $88 \pm 4$ & - & - & 2 \\
\hline & & & Compres $\because$ & $611 \pm 58$ & $633 \pm 57$ & $0.4 \pm 0.04^{c}$ & 3 \\
\hline
\end{tabular}

a. At the end of the test.

b. Calculation of ultimate strength at $1.5 \%$ strain to preclude barrelling effects.

c. At the drop in load or the end of the test, whichever occurred first. 


\section{References}

1. G. R. Longhurst, Beryllium Technology Workshop, Clearwater Beach, Florida, November 20, 1991, EGG-FSP-10017, December 1991.

2. J. M. Beeston, G. R. Longhurst, R. S. Wallace, and S. P. Abeln, "Mechanical Properties of Irradiated Beryllium," Journal of Nuclear Materials, 195, 1992, pp. 102--108. 


\title{
ACTIVATION PRODUCT CHEMICAL REACTIVITY, VOLATILITY, AND TRANSPORT
}

\author{
Researchers: R. Smolik, R. S. Wallace, \\ S. J. Piet, and K. A. McCarthy, INEL
}

Deuterium-tritium 14-MeV fusion neutrons will produce activation products in materials. Since activation products are an accident concern, research must examine potential behavior of activation products during an accident. Thus, we study formation and transport of mobile activation products. We also study chemical reaction rates for potential energy release or hydrogen production. This task focuses on materials for the divertor, first wall, blanket, and shield, and their behavior at high temperatures during accidents and in oxidizing gases like air and steam.

The relative desirability of a material is influenced by the potential for mobilization and transport of activation products associated with that material. Tests conducted on the Volatilization of Activation Product Oxides Reactor (VAPOR) apparatus show the potential for mobilizing activation products from various fusion alloys. We also began to investigate transport of activation products using the VAPOR facilit in fiscal year 1992 to evaluate the desirability of siveral materials. This task gives initial evidence for safety assessments of accident activation product behavior (i.e., estimating possible radioactivity releases in accidents). The data have been applied to the proposed International Thermonuclear Experimental Reactor (ITER), the Burning Plasma Experiment/Tokamak Physics Experiment, and to commercial design studies like ARIES.

\section{Major Accomplishments}

Volatility and Chemical Reactivity Tests of Plasma-Sprayed Beryllium and Tungsten. Plasma spraying is a possible in situ method for repairing plasma-facing surfaces. In these tests we studied the volatility and chemical reactivity of plasma-sprayed beryllium and tungsten exposed to steam.

Beryllium has recently received much attention as a plasma-facing material, so we are looking at its safety implications. Although beryllium has low activation levels, it is quite chemically toxic. We studied tungsten because it had the highest activation product inventory in the Conceptual Design Activity (CDA) ${ }^{1}$ and in ARIES-I. ${ }^{2}$ We have previously studied beryllium in fully dense and porous forms $s^{3,4}$ and a tungsten alloy in fully dense form. ${ }^{5}$

Battelle Columbus prepared the plasmasprayed beryllium samples. We used immersion density methods to characterize samples from each of five different spraying conditions. We measured porosity levels of $9-15 \%$ and tested two samples with conditions representing the worst and best deposits, as indicated by density, in steam between 500 and $600^{\circ} \mathrm{C}$.

The plasma-sprayed beryllium specimens were very reactive in the steam environment. We generally hold samples near $550^{\circ} \mathrm{C}$ in steam as a stabilizing step before heating them to a 
desired test temperature. Hydrogen gas evolution from the initial plasma-sprayed sample of beryllium at $550^{\circ} \mathrm{C}$ showed that the material was reacting. We have never observed evidence of reaction at such a low temperature, even for the $88 \%$ dense material produced by powder metallurgy that we have tested. Figure 4 shows reaction rates for various types of beryllium tested in high-temperature steam.

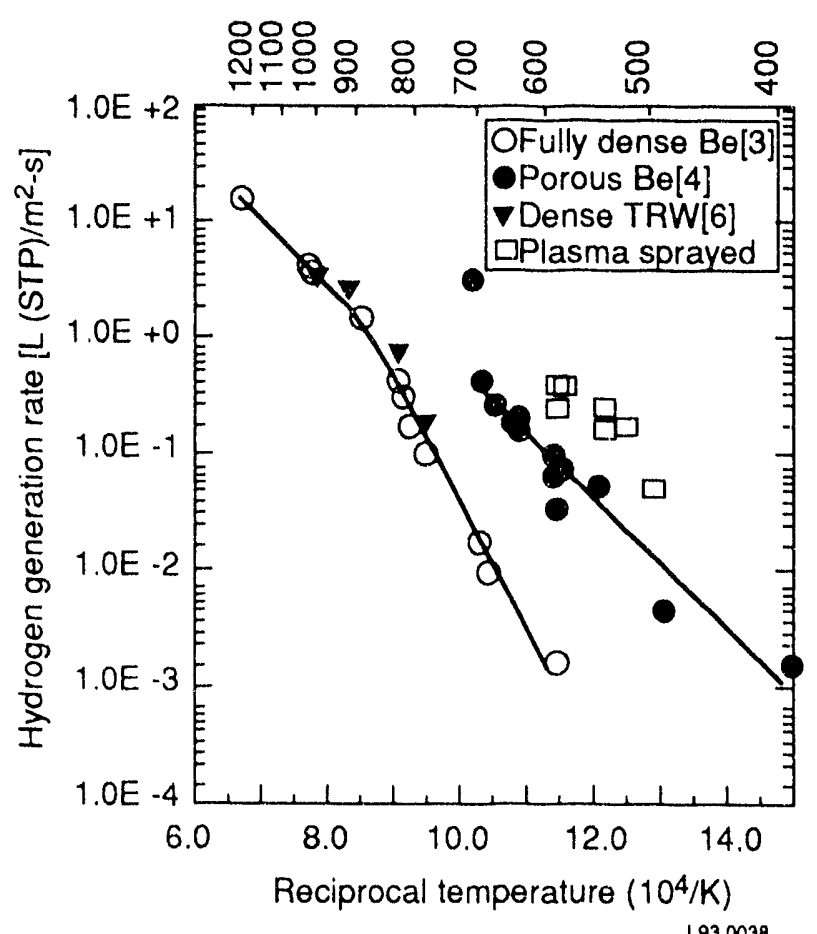

Figure 4. Reaction rates of various forms of beryllium in a steam environment. (Note: The numbers in the legend in brackets refer to references.)

We attribute the high reactivity of the plasma-sprayed beryllium samples to the high porosity that allowed the steam easy access. The samples readily broke into pieces and powdery fragments following the tests. This indicated that reaction had occurred throughout the specimens. The beryllium oxide powder was also very fine, much more so than the product resulting from the $88 \%$ dense beryllium formed by powder metallurgical methods. This shows that the plasma-sprayed samples were comprised of very fine particles that also contributed to the high reactivity. The unacceptably high reactivity of the plasma-sprayed beryllium samples indicates that additional efforts are needed to demonstrate or develop the capabilities to produce good dense deposits.

The plasma-spray tungsten samples were prepared by Sandia National Laboratory. These samples were sprayed under reduced pressures in a vacuum-spray chamber and resulted in higher theoretical densities than the plasma-sprayed beryllium. We measured apparent porosities of $2-6 \%$. We tested the tungsten samples in steam at temperatures from 800 to $1,200^{\circ} \mathrm{C}$.

The plasma-sprayed tungsten-steam reaction rates were very similar to reaction rates of a hot-rolled tungsten sample. They were slightly lower than the reaction rates we deduced from previously tested tungsten alloy samples. ${ }^{7}$ The volatility of the tungsten in the plasma-sprayed samples also was similar to the tungsten volatility in the tungsten alloy. The lower porosity levels in the plasma-spray tungsten relative to those existing in the beryllium samples apparently prevented the penetration of steam; thus, they behaved more like fullydense samples than did the beryllium plasmasprayed samples.

\section{Tests of the Reaction Rates and Volatility of} Niobium with Air and Steam. Niobium is a candidate for use as a structural material in plasma-facing components. We had a $\mathrm{Nb}-\mathrm{ZZr}$ alloy prepared with elements added to simulate changes in composition that could result from transmutations caused by irradiation. The elements we added are those we expect to form that may be important for safety assessments: molybdenum, yttrium, manganese (to represent technetium), and strontium. Attempts to include strontium were not successful because of its high volatility. (Fiscal year 1993 work will address preparing alloys with highly volatile 
constituents.) These samples were tested for hydrogen release in reactions with steam, and volatility in air and steam for a temperature range of $800-1,200^{\circ} \mathrm{C}$.

The expression derived from our tests for the rate of hydrogen generation when reacted in high-temperature steam at pressures near one atmosphere is given below. ${ }^{8}$ This equation is valid for temperatures from 800 to $1,200^{\circ} \mathrm{C}$.

$R=100 \exp \left(\frac{-9,170}{T}\right)$

where

$$
\begin{aligned}
& \mathrm{R}=\mathrm{H} \text { generation }\left(\mathrm{L} / \mathrm{m}^{2}-\mathrm{s}\right) \\
& \mathrm{T}=\text { temperature }(\mathrm{K}) .
\end{aligned}
$$

Figure 5 shows the hydrogen generation rates for several candidate plasma-facing materials when reacted in steam. The hydrogen generation rate of the niobium alloy is among the lowest of the plasma-facing component materials we have tested. The total amount of hydrogen generated in an accident will depend on many parameters, and it is necessary to model the particular geometry. Fiscal year 1993 work will include the development of a model to look at sensitivities to various parameters.

The volatilization rates of molybdenum and niobium from the niobium alloy in steam are one to two orders of magnitude higher than those we observed in air. Although molybdenum is present at only $0.12 \mathrm{wt} \%$, the quantities of this element volatilized in air are nearly comparable to the quantities of niobium volatilized. The molybdenum volatility in steam is only three to four times smaller than that of niobium in steam.

Copper and molybdenum are the two other primary candidates for the divertor substrate

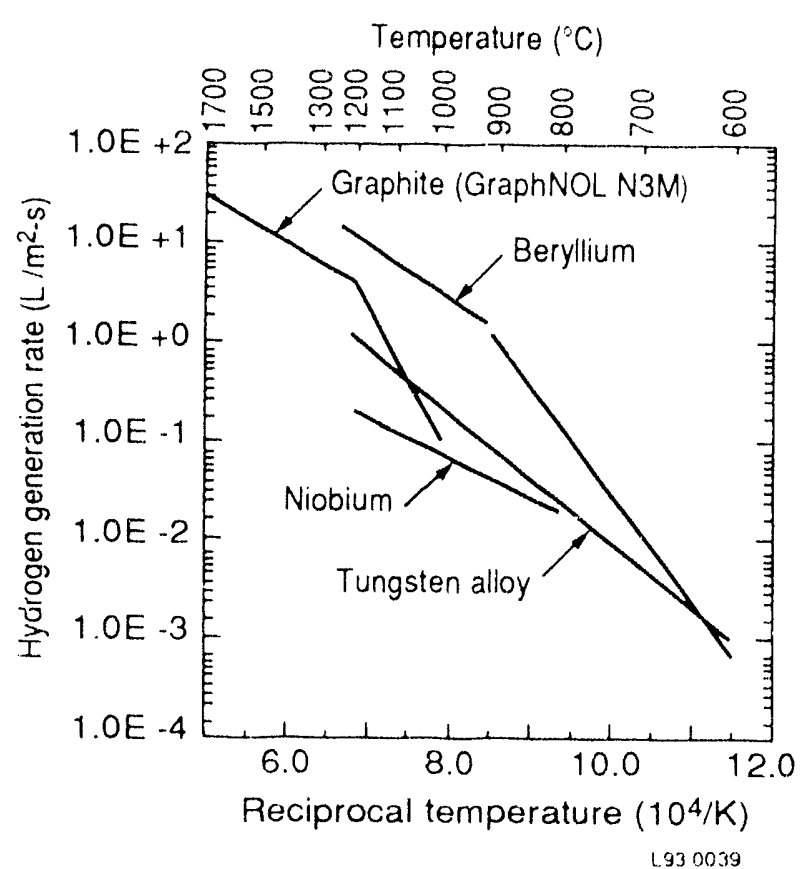

Figure 5. Hydrogen generation rates for several candidate plasma-facing materials.

identified in the CDA. ${ }^{1}$ We have not tested a molybdenum alloy, but the literature indicates that molybdenum is an extremely reactive metal and that its oxide, $\mathrm{MoO}_{3}$, is very volatile. This information, in addition to the high volatility of the molybdenum in the niobium alloy (and in our earlier steel tests ${ }^{9}$ ), indicates that molybdenum would be easily volatilized. The high volatility and reactivity of molybdenum coupled with the radiological hazard of molybdenum make it extremely undesirable as a structural material.

Volatility is important because it determines dose releases in an accident. Figure 6 gives the maximum mobilized dose as a function of temperature for niobium and copper in air and steam, based on our volatility measurements. We assumed all of the strontium was volatilized. We also have assumed a one-week lossof-coolant accident (LOCA) involving the entrance of air or steam into the plasma chamber. The fluence is $1 \mathrm{MW}-\mathrm{yr} / \mathrm{m}^{2}$. The divertor area is $200 \mathrm{~m}^{2}$, and the material 


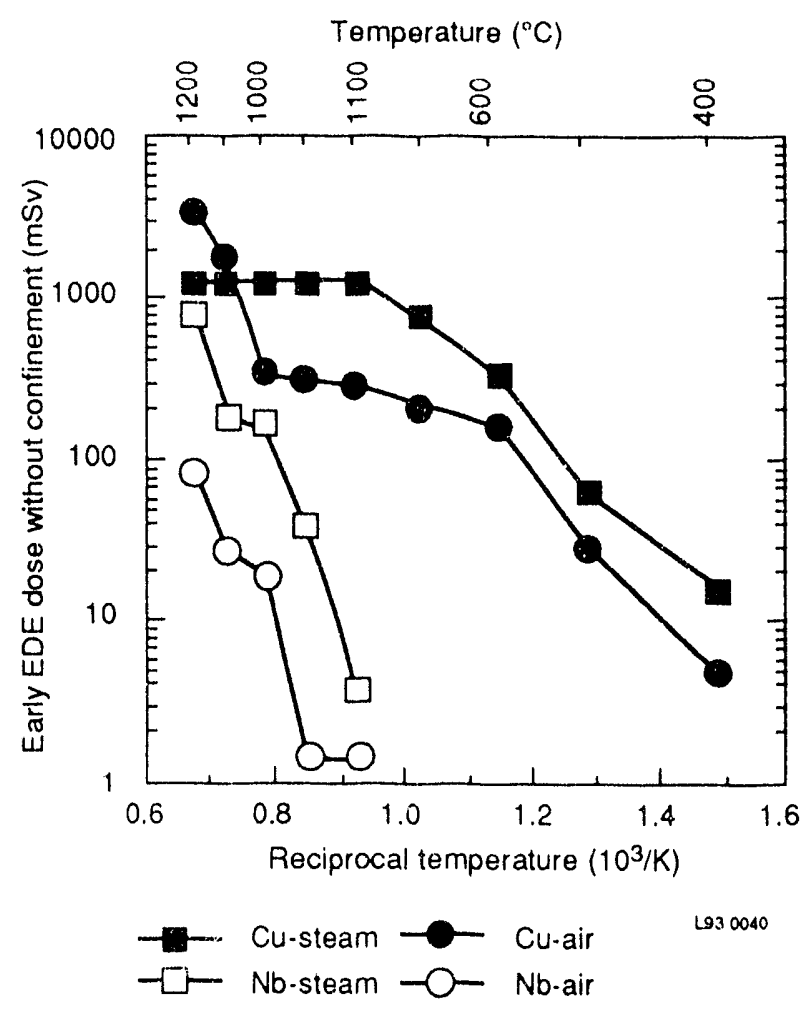

Figure 6. Maximum mobilized dose for niobium and copper in air and steam.

thickness is $0.005 \mathrm{~m}$. No credit has been taken for confinement (thus the graphs show maximum mobilized dose, not necessarily dose released to the environment), the primary aim of this analysis being a qualitative comparison. In both the air and steam cases, the dose released is less for niobium than copper. Accident temperatures will most likely be below $1000^{\circ} \mathrm{C}$, and there is generally at least an order of magnitude difference between the copper and niobium alloys at these temperatures.

From these perspectives, niobium appears more desirable than copper or molybdenum as a divertor substrate material. (Other factors include tritium inventory and permeation, resistance to runaway electrons, and time before damage during a LOCA.) The mobilized dose is significantly less for niobium than copper. The high volatility and dose hazard of molybdenum indicate that it would be much less attractive than either copper or niohium.

\section{Exploratory Study of Burn Time, Duty} Factor, and Fluence on ITER Activation Hazards. The safety analyses for the CDA of ITER were based on the simplifying assumption that the activation of materials occurs continuously. Since the analyses showed a significant hazard, it is appropriate to examine how much hazard reduction might occur if this conservative assumption were relaxed. This study explored how much reduction might be gained by considering noncontinuous operation (i.e., by considering plasma burn time, duty factor, and integrated fluence). ${ }^{10}$

Figure 7 shows the effect of isotope halflife, burn time, duty factor, and fluence on inventory ratio (pulsed/continuous). Ratios less than 1 indicate reduction from the continuous case. The total fluence is kept constant within each case. Assuming that ITER keeps a technology mission, the main factor to consider in reducing hazards and risk from the CDA values is the duty factor. If we neglect accidents during maintenance and reliability penalties for cyclic operation, a duty factor of $20-30 \%$ reduces the amount of time per year that ITER is at most risk by factors of $3-5$. Such a duty factor also contributes to lowering the specific dose by factors of 1.0 to 14 , depending on material and hazard measure. The corresponding risk reduction factors might range from 3 to 70 in the most extreme cases for specific elements from specific alloys. Therefore, if we assume that ITER keeps a technology mission, then accounting for burn time, duty factor, and fluence (versus the CDA assumption of continuous irradiation toward 3.0-yr fluence) probably lowers activation risk by about one order of magnitude at best. This reduction wil! be particularly useful in countering other trends that will worsen the risk picture: risk from maintenance and shutdowns (not included in the CDA), penalties from cyclic operation (not 


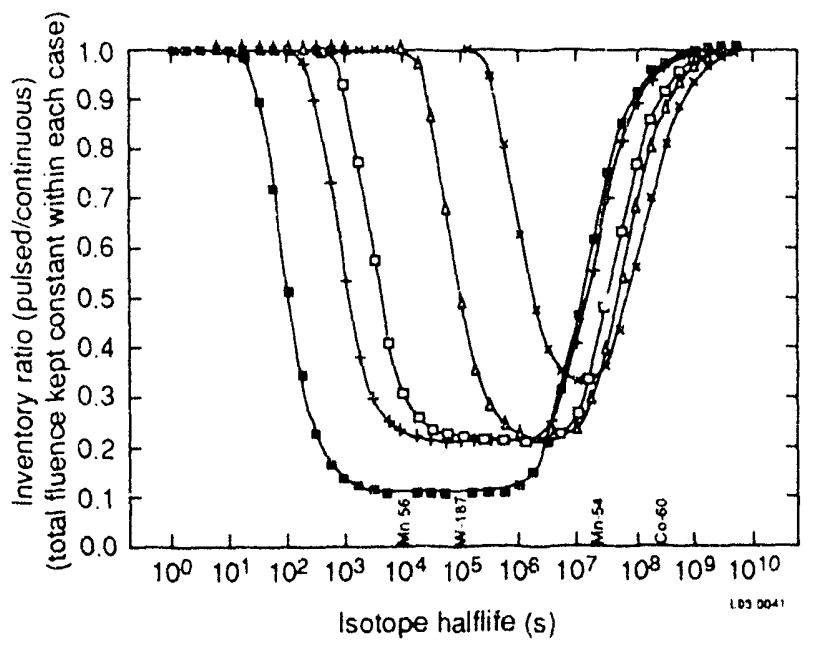

$\begin{array}{lcc}\text { Burn time } & \text { Duty factor } & \text { Fluence (yr) } \\ \text { - } 100 \mathrm{~s} & 10 \% & 0.1 \\ +1000 \mathrm{~s} & 20 \% & 0.3 \\ \text { - } 1 \text { hour } & 20 \% & 0.7 \\ \text { 1 1 day } & 20 \% & 1.0 \\ \times 2 \text { weeks } & 30 \% & 3.0\end{array}$

Figure 7. The effect of isotope halflife, burn time, duty factor, and fluence on inventory ratio.

included in the CDA), and possibly larger size and higher neutron flux.

Exploratory Transport Tests. In meeting safety goals for ITER, we must show a 2-3 order of magnitude radioactivity confinement factor. ${ }^{1}$ To ensure that we have the necessary information to support an environmental impact statement and preliminary safety analysis report, a well thought out and aggressive testing schedule is needed. We put together a strategy for developing adequate activation product radioactivity confinement. This strategy involves deciding what tests and computer codes will be necessary.

As part of this strategy, we upgraded our VAPOR facility to enable us to carry out transport tests. We have incorporated a cascade impactor that classifies particles or agglomerates according to size. The impactor substrates and filter are examined after each test with scanning electron microscopy techniques to provide information on primary particle and agglomerate sizes, as well as chemical form. This information will be r.:ed in transport codes.

Tests to date have been exploratory in nature. Our intent is to identify the best methods for determining particle and agglomerate sizes and chemical form. We used tungsten in our first tests because we know it is highly volatile. Analysis of the deposits on impactor substrates will help determine the physical and chemical form of the material. In the tungsten-steam test, $75 \%$ of the agglomerated particles were $1 \mu \mathrm{m}$ or smaller. The worst-case size is about $0.02 \mu \mathrm{m}$; aerosols this size will travel the farthest considering the trade-off between gravitational settling and diffusion. ${ }^{11}$ Our preliminary results show that the agglomerated aerosols of less than $1 \mu \mathrm{m}$ consist of about $2 \%$ primary particles with sizes less than $0.04 \mu \mathrm{m}$.

\section{Future Activities}

Work will continue to focus on ITERrelevant materials. We will continuc our exploratory transport tests. Additionally, we will investigate possible aerosol formation from mechanically spalled oxides, which could prove to be very significant. Because tokamak dust and corrosion products could be important activation product mobilization pathways, we will explore what can be done in these areas.

In the past, we have had some difficulties incorporating elements that are highly volatile into our samples. We will work on improving alloy preparation techniques so that we can consistently prepare alloys containing all important materials. In the same manner, we will work on lowering detection limits for 
certain elements. At lower temperatures, the amount of volatilized mass is often below detection limits. Certain elements are hazarduus even at low concentrations; therefore, it is useful to lower detection limits. For example, releasing the entire radioactive inventory of ITER would result in an offsite dose of about $1,000 \mathrm{~Sv}$. The goal is to limit the offsite dose to $10 \mathrm{mSv}$. That means approximately $99.999 \%$ retention. We must have detection limits capable of showing this is possible.

Many LOCA analyses have been done by different people with differing results. To understand the sensitivities to various parameters such as coolant type, first wail armor material, and boundary conditions, we will complete the development of an ITER midplane LOCA model. The model will give hydrogen produced and chemical energy released in addition to temperature profiles. This task is very important because it incorporates what we have donc in init experiments and gives us a tool to understand how various design parameters affect temperatures.

In support of low activation materials, we will carry out vanadium alloy-air tests to measure volatility. This information will be used in support of a study to look at the safety aspects of vanadium recycle. The potential of low activation materials may lead to fusion being passively safe, or even inherently safe.

A significant amount of work has been done in the activation products task over the years. The volatility and chemical reactivity work through 1992 will be put together in a form that can be used by others for safety assessments. 


\section{References}

1. J. Raeder and S. J. Piet (eds.), ITER Safery Analyses, ITER Documentation Series, No. 36, International Atomic Energy Agency, Vienna, 1991.

2. The ARIES-I Tokamak Reactor Study, UCLA-PPG-1323, 1991.

3. G. R. Smolik, B. J. Merrill, and R. S. Wallace, "Implications of Beryllium: Steam Interactions in Fusion Reactors," 5th Intemational Conference on Fusion Reactor Materials, Clear Water, Florida, November 17-22, 1991.

4. G. R. Smolik, B. J. Merrill, and R.S. Wallace, Reaction of Porous Beryllium in Steam, EGG-FSP-10346, July 1992.

5. G. R. Smolik, S. J. Piet, and R. M. Neilson, Jr., "Predictions of Radioactive Tungsten Release for Hypothetical ITER Accident," Fusion Technology, 19, 3, 1991, pp. 1398-1402.

6. J. L. Blumenthal and M. J. Santy, An Experimental Investigation of the Behavior of Beryllium in Simulated Launch Pad Abort Environments, TRW Systems, Sandia Corporation Report, SCDC-65-1637, July 1965.

7. G. R. Smolik, Tungsten Alloy Oxidation Behavior in Air and Steam, EGG-FSP-10166, March 1992.

8. G. R. Smolik and K. A. McCarthy, Oxidation and Volatilization of a Niobium Alloy, EGG-FSP-10341, July 1992.

9. S. J. Piet et al., Initial Experimental Investigation of the Elemental Volatility from Steel Alloys for Fusion Safety Application, EGG-FSP-8459, April 1989.

10. S. J. Piet, Exploratory Study of Burn Time, Duty Factor, and Fluence on ITER Activation Hazards, EGG-FSP-10396, August 1992.

11. S. J. Fiet and S. I. Brereton, Fusion Radioactivity Confinement and Application to Postulated ITER Accidents, EGG-FSP-9470, March 1, 1991. 


\section{LIQUID METAL CHEMICAL REACTIONS}

\section{Researchers: M. L. Corradini, G. Vukovic, and J. Murphy, UW; K. A. McCarthy and L. C. Cadwallader, INEL}

The liquid metal chemical reactions program has studied hazards associated with liquid lithium and lithium-lead considered for use as tritium-breeding materials and with various metals considered for use as a coolant. These hazards include hydrogen production, overpressure, and materials volatilization through chemical heat generation.

Past work 'has focused on liquid metals suitable for use as both breeder and coolant. Liquid metals for use as a coolant only have gained significant attention recently; thus. the University of Wisconsin (UW) concentrated on coolant candidate liquid metals. The objective of the work was to determine if significant thermal interactions or chemical reactions result when the candidate liquid metals come into contact with water.

\section{Major Accomplishments}

UW has designed and constructed a shock tube to investigate liquid metal/water interactions. ${ }^{1,2}$ The tube's geometry lends itself to a one-dimensional interaction of the metalwater system under well-controlled initial and boundary conditions. In addition, it allows for unambiguous measurement of the pressures developed from the interaction and the explosion work from the expansion of the interaction products. The measurement of chemical reactivity is determined by post-test chemical analysis.

In the tube, a column of water is accelerated by a pressure difference. This column then impacts the liquid metal surface in a way that can be described using one-dimensional geometry. The mass (column height) and temperature (saturated to ambient conditions) of the water can be varied. The metal volume also can be varied $\left(20-100 \mathrm{~cm}^{3}\right)$ as can its temperature (melting temperature to $1200^{\circ} \mathrm{C}$ ). The driving pressure difference may be between 0.1 and 2.0 MPa gage (up to $1.1 \mathrm{MPa}$ has been tested to date).

The water impact causes rapid mixing of the two liquids at the interface and triggers a rapid fragmentation of the hot metal, which in turn explosively vaporizes some of the water coolant that has been mixed. Under this inertial constraint, the vaporization event occurs at high pressures (20-50 $\mathrm{MPa})$, and the subsequent expansion work from this event is measured within the closed volume apparatus.

UW tested lead, tin, indium, and gallium in the shock tube apparatus. The initial series of experiments indicates the energetics are relatively small, and there are minimal indications of a chemical reaction.

A chemical analysis of the fragmented material is being done. This will quantify the amount of chemical reaction. Figure 8 shows results of a typical $\mathrm{Ga} /$ water test. The figure indicates the pressure in the region of interaction and the inert gas plenum pressure above the water column. The multiple pressure spikes occur because the vapor produced from the event expands and pushes the water upward until an overexpansion drives the column back down onto the fresh unfragmented and unquenched metal. This continues until the metal is consumed and the pressures equilibrate. 


\section{Future Activities}

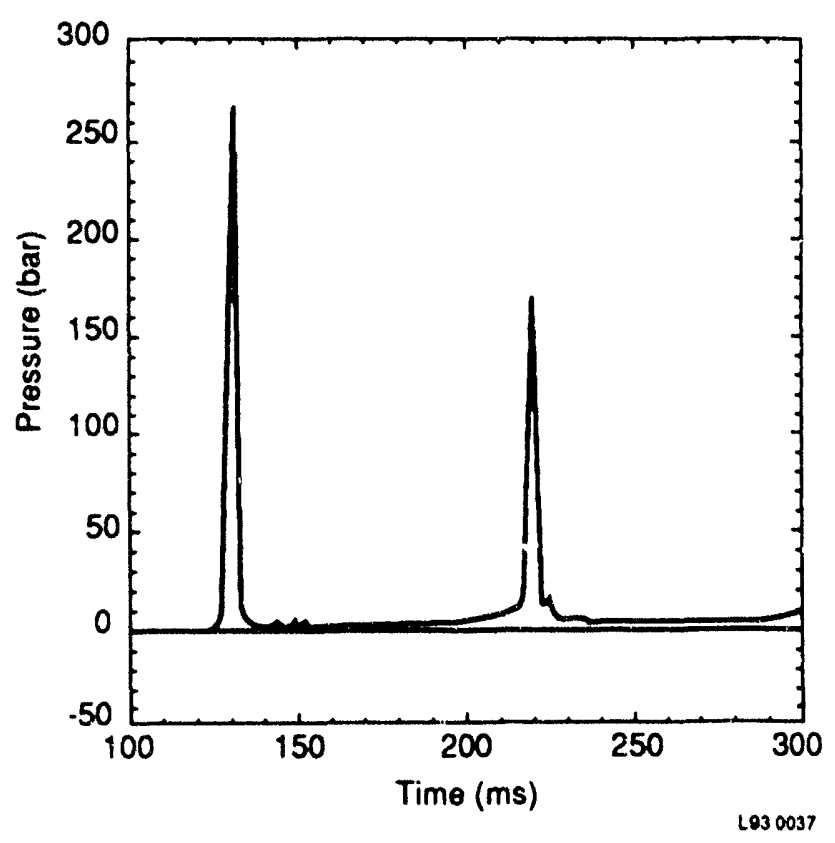

Figure 8. Pressure in a typical Ga/water test $\left(\mathrm{Ga}\right.$ at $\left.600^{\circ} \mathrm{C}\right)$.
UW will test 100-200 gram scale lithium lead samples. This work will test the assumption of mass independent chemical reaction kinetics values observed in previous lithium-water tests. ${ }^{3}$

Related to this work is the development of a computer model to combine liquid metal chemical reactions with fluid jet hydrodynamic breakup. UW will complete this model in the upcoming year using empirical data from experiments. The model then will be used to analyze liquid metal-water interactions that occur heterogeneously; this includes lithium lead-water reactions.

Bercause of renewed interest in liquid metals for fusion applications, we are considering additional liquid metal work. Possible topics are bismuth and polonium-210 removal from lithium-lead and lead, cleanup of gallium and lead, and gallium-air interactions. 


\section{References}

1. Michael Raz, Vertical Shock Tube Mechanical Design for Liquid-Metal/Water Interactions, UWRSR 69, March 1991.

2. Gordana Vukovic, Liquid-Metal/Water Interactions in a Shock-Tube Geometry, UWRSR 71, August 1991.

3. S. W. Lomperski, Molten-Lithium/Water Interaction Experiments: Explosive Reactions and Reaction Rate Measurements, UWFDM-851, May 1991. 


\section{MAGNET SAFETY RESEARCH}

\section{Researchers: L. C. Cadwallader and J. Stephen Herring, INEL; R. J. Thome, A. Shajii, and J. P. Freidberg, MIT}

Fusion reactors will require large sets of superconducting magnets for plasma confinement and control. These arrays of superconducting coils will store over $100 \mathrm{GJ}$ in their magnetic fields. The safe discharge of that stored energy in a transient and reliable routine operation of those magnet sets is essential for the commercial viability of fusion power. Magnet designers need to accurately simulate many types of transients, including routine charges and discharges, quench propagation, off-normal and emergency energy dumps, real-time instrumentation, and internal coil shorts and arcs.

\section{Major Accomplishments}

The work on the safety of superconducting magnets focused on two areas during fiscal year 1992: collection of failure rate data on operating magnet systems, and development of a computer code to determine the energy deposition and hot-spot temperature resulting from a spreading resistive zone in a winding.

Failure Rate Data. The International Thermonuclear Experimental Reactor (ITER) toroidal field (TF) magnets will be among the largest (about 400 tonnes each) ever made and each will contain about $6 \mathrm{GJ}$ of stored energy. The large amount of stored energy and the difficulty in replacing failed magnets suggest the importance of using risk analysis to identify and avoid problems. Internal magnet faults, such as a short circuit, could cause a magnet to fail without harm to other equipment, but would lead to long machine downtime. Other magnet faults could release the large amount of stored energy, thus posing a threat to nearby systems.
In developing a failure rate data base for risk analysis, the following items are used to produce a set of magnet and magnet-related initiating events (IEs):

- Operating experience review

- Safety document review

- Expert testimony

- Engineering judgment

- Fault interaction matrix.

Magnet Faults Affecting Tokamak Systems. Table 2 is an adaptation of the fault interaction matrix (FIM) ${ }^{1,2}$ The FIM is a representation of the kinds of interactions that are possible among tokamak systems. Experience shows us that faults originating in magnets can affect other systems. The first two rows of Table 2 illustrate the many interactions possible from the magnet sets to other tokamak systems.

Medical technology magnet experience shows the danger of unsecured ferrous objects in the fringe magnetic field, such as oxygen bottles, traction weights, and gurneys. Similarly, the Princeton Large Torus experienced a lossof-vacuum accident in September 1979 when a wrench left near the machine was accelerated by the magnetic field and shattered a glass viewing port. Another event occurred at the D-III-D reactor when the changing magnetic field moved a wrench through the electrical buswork on the level below the reactor, causing a short circuit. Table 2 lists wrench or other missile impacts to the vacuum vessel, coolant piping, and electric power systems as " $\mathrm{M}$ " interactions. 
Table 2. Fault interaction matrix for off-normal operation of ITER systems. a,b

\begin{tabular}{lccccccccccc}
\hline & \multicolumn{7}{c}{ ITER system impacted by the faulted system } \\
\cline { 2 - 9 } ITER system having a fault & PF & TF & VV & DR & IC & DG & CS & PH & PF & EP \\
\hline Poloidal field coils (PF) &.- & E,M,P & E,M,P & E,P & E & E & E,M & E & E & E,M \\
Toroidal field coils (TF) & E,M,P &.- & E,M,P & E,P & E & E & E,M & E & E & E,M \\
Vacuum vessel (VV) & M & M &.- & M & M & M & M & M & M & NA \\
Divertor (DR) & T & T & M,T & -- & M & M & T & NA & NA & NA \\
Instrumentation and control (IC) & P,C & C & P & P & -- & P & C & C & C & C \\
Diagnostics (DG) & C & C & P & P & C & -- & C & C & C & C \\
Cryogenics system (CS) & T & T & T & T & T & T & -- & T & T & NA \\
Plasma heating (PH) & P & P & P,T & P & P & P & NA &.- & NA & NA \\
Plasma fueling (PF) & P & P & P,M & P,T & P,T & P,T & NA & NA &.- & NA \\
Electric power (EP) & E,P & E,P & P & P & E & E & E & E & E & $\cdots$
\end{tabular}

a. $\mathrm{C}=$ control errors resulting in off-normal operation

$\mathrm{E} \quad=$ electromagnetic interaction resulting in induced currents and associated off-normal power

$\mathrm{M}=$ direct application of mechanical stress

$\mathrm{NA}=$ not applicable, no interaction anticipated

$\mathrm{P} \quad=$ coupled through off-normal plasma behavior such as disruptions or plasma positioning errors

$\mathrm{T}=$ thermal transients such as off-normal heat loads or off-normal cooling.

b. The "-." symbol that runs diagonally through the FIM stands for "within system faults."

Large magnets have disassembled in severe structural failure events. This type of event occurred in December 1982 for a U.S. magnetocryogenic hydrodynamics magnet. ${ }^{3,4}$ The magnet in question had a unique, reconfig. urable design for use with either water or liquid nitrogen coolant. Unfortunately, the design allowed transverse stresses in excess of the ultimate tensile strength of the keys and fingers that held the magnet sections together. Failure of the aluminum fingers allowed a section to be propelled outward. The movement was arrested by other structural members and the conductor itself.
Two recent European analyses have investigated various magnet failure modes in the Next European Torus (NET) and ITER. Mitchell et al. ${ }^{5}$ concluded that a keyed TF structure could provide sufficient redundancy to allow adequate TF coil structural support in the case of a major structural failure. Kramer et al. ${ }^{6}$ noted that local instability of the central vault could initiate a loss of integrity.

Magnet body missile and magnet movement impacts to surrounding systems also are listed as potential " $M$ " interactions in Table 2. 
The Joint European Torus (JET) plasma physics experiment at Culham suffered a vacuum vessel shift as a result of a bad poloidal field (PF) coil command in June 1984. The PF coil control system received an improper command, and the PF magnets responded correctly to the improper command. The plasma moved downward $1 \mathrm{~m}$ in $20 \mathrm{~ms}$, then disrupted against the inner vessel wall. The disruption force against the vacuum vessel (VV) caused it to move upward about $6 \mathrm{~mm}$, and there was some slight permanent VV deformation.' Such interactions between the PF and VV systems are indicated by an " $E$ " under the VV column in Table 2.

\section{Initiating Events and Estimated} Frequencies. IEs are internal or external faults that can propagate into events that threaten workers, the public, the environment, or equipment. Magnet IEs have been identified through safety document review, ${ }^{8,9}$ operating experiences, ${ }^{3,10}$ and engineering judgment. Magnet expert testimony would be very helpful for future assessments and regulatory action.

Table 3 gives the collection of these IEs that originate inside the magnet systems and those IEs that can significantly affect the magnet systems with their best estimate frequencies of occurrence.

Frequencies are based on operating experience from particle accelerators, fusion experiments, safety work for NET, the fission power industry, some limited expert opinion input, and engineering judgment., ${ }^{3,10}$ Further cooperative work with fusion magnet designers should lead to refinement of these values. An expert opinion survey is planned to solicit magnet designer input for ITER safety work and to support the International Energy Agency Implementing Agreement on Environment, Safety, and Economic Aspects of Fusion Power Task 7 (failure rate data base).

The IE frequencies in Table 3 apply to the May 1992 ITER magnet design of 24 TF coils, with about $9.5 \mathrm{~km}$ of cable in conduit conductor per coil, and internal helical tubing for additional helium flow. ${ }^{11}$ The eight PF coils also are included for the IE frequency calculations. The yearly IE frequencies usually apply to the entire ITER facility; exceptions are marked. With magnet designer input and ITER design evolution in the Engineering Design Activity (EDA), these values may require revision.

Internal IEs were quantified based on data given in References 3 and 10 . External IEs were quantified based on the authors' experience with risk assessment of Idaho National Engineering Laboratory facilities. The external event frequencies are generally representative values for U.S. nuclear reservations. When specific ITER sites are chosen, these external event IE frequencies will be revised based on detailed site-specific analyses.

\section{Internally-Cooled Conduit Superconductor Quench Code Development. Researchers at} the Massachusetts Institute of Technology (MIT) have been developing a code to model quench propagation in cable-in-conduit superconductors. They have benchmarked the code against codes developed by Lawrence Livermore National Laboratory (LLNL) and the NET team. The first objective of the MIT code is to run much faster than the other two codes in modeling quench propagation. The MIT code also will model parallel helium passages in which there is lateral transport of heat and mass between the main interstitial helium channels in the cable-in-conduit conductor cable and an auxiliary helium channel such as is found in the U.S. demonstration poloidal cable and the superconducting supercollider bus.

The LLNL and MIT codes were tested against data taken at MIT on the simulated bus for the superconducting supercollider dipole magnets. Both codes predicted energy margin very well. Energy margin is the amount of energy required as local input to initiate a propagating normal zone. Results are summarized in the MIT Annual Report. ${ }^{12}$ 
Table 3. Potential ITER magnet initiating events.

\begin{tabular}{|c|c|c|c|}
\hline Potential initiating event & Possible IE causes & $\begin{array}{l}\text { Suggested } \\
\text { identifier }\end{array}$ & $\begin{array}{l}\text { Frequency } \\
\text { per year }\end{array}$ \\
\hline \multicolumn{4}{|c|}{ Magnet IEs that could damage other systems } \\
\hline Magnet structural failure accident & Structural flaw or overcurrent & MSFA & $1 \mathrm{E}-06^{*}$ \\
\hline Magnet shifts position & $\begin{array}{l}\text { Pedestal fault or unbalanced forces on } \\
\text { magnet }\end{array}$ & MSP & $5 \mathrm{E}-04$ \\
\hline Magnetic field generated missiles & Loose ferritic parts or human error & MFGM & $1 \mathrm{E}-01$ \\
\hline Magnet quench accident & $\begin{array}{l}\text { Localized hot spots on coils from runaway } \\
\text { electrons or frictional heat from conductor } \\
\text { movement }\end{array}$ & MQA & $\begin{array}{ll}2 \mathrm{E}-01 & \mathrm{TF} \\
8 \mathrm{E}-01 & \mathrm{PF}\end{array}$ \\
\hline Loss of magnet coolant & Pipe rupture, fitting leak, or human error & LOMC & $1 \mathrm{E}-02$ \\
\hline Loss of magnet coolant flow & Inadvertent valve closure or human error & LMCF & $1 \mathrm{E}-02$ \\
\hline $\begin{array}{l}\text { Magnet coolant pressurization } \\
\text { event }\end{array}$ & $\begin{array}{l}\text { Coolant phase change from radiation or other } \\
\text { heat leak }\end{array}$ & MCPE & $1 \mathrm{E}-02$ \\
\hline Loss of insulating vacuum & $\begin{array}{l}\text { Air inleakage through jacket or helium (or } \\
\text { nitrogen) outleakage from inner piping }\end{array}$ & LIVA & $3 \mathrm{E}-03$ \\
\hline Magnet open circuit event & $\begin{array}{l}\text { Thermal or mechanical cycling, vibration, or } \\
\text { wearout }\end{array}$ & MOCE & $5 \mathrm{E}-02$ \\
\hline Magnet short circuit event & $\begin{array}{l}\text { Local breakdown, hot spot, or instrumentation } \\
\text { lead fault }\end{array}$ & MSCE & $1 \mathrm{E}-03$ \\
\hline $\begin{array}{l}\text { Magnet charging/discharging tran- } \\
\text { sients }\end{array}$ & Electronics fault, human error, or arcing & MCDT & $1 \mathrm{E}-02$ \\
\hline \multicolumn{4}{|c|}{ Other IEs that could damage the magnets } \\
\hline Loss of offsite power & $\begin{array}{l}\text { Loss of grid, transformer fault, human error, } \\
\text { or other electrical faults }\end{array}$ & LOSP & $1 \mathrm{E}-00$ \\
\hline Loss of control power & $\begin{array}{l}\text { Circuit breaker fault, human error, or elec- } \\
\text { trical faults }\end{array}$ & LOCP & $1 \mathrm{E}-00$ \\
\hline Facility blackout event & $\begin{array}{l}\text { Human error, or loss of system pressure and } \\
\text { combined equipment faults }\end{array}$ & FBE & $1 \mathrm{E}-01$ \\
\hline Fire inside building ${ }^{\mathrm{b}}$ & Electrical short circuit or human error & FIRE/IN & $3 \mathrm{E}-02$ \\
\hline Fire outside building & Forest fire or range fire & FIRE/EX & $1 \mathrm{E}-04$ \\
\hline Seismic event & Earthquake & SE & $1 \mathrm{E}-04$ \\
\hline Flood inside building & $\begin{array}{l}\text { Piping breach or inadvertent fire suppression } \\
\text { system actuation }\end{array}$ & FLOOD/IN & $3 \mathrm{E}-01$ \\
\hline Flood outside building & River flood, tsunami, etc. & FLOOD/EX & $1 \mathrm{E}-03$ \\
\hline High winds & $\begin{array}{l}\text { Tornado, hurricane, seiche, etc., wind over } \\
160 \mathrm{kph}\end{array}$ & WIND & $1 \mathrm{E}-03$ \\
\hline Snow/ice & $\begin{array}{l}\text { Snow or ice accumulation on buildings, stacks, } \\
\text { electrical switchyard, etc. }\end{array}$ & SNOW & $1 \mathrm{E}-01$ \\
\hline Lightning & Lightning from a storm causes electrical surges & LTNG & $1 \mathrm{E}-01$ \\
\hline Aircraft impact & $\begin{array}{l}\text { Aircraft strikes reactor building or support } \\
\text { building. ITER should be sited far away from } \\
\text { aircraft flight paths }\end{array}$ & AlRC & $1 \mathrm{E}-06^{n}$ \\
\hline External missiles & $\begin{array}{l}\text { Turbine blade or high speed otject impacts } \\
\text { like large hailstones }\end{array}$ & MISL & $1 \mathrm{E}-04$ \\
\hline
\end{tabular}




\section{Future Activities}

During fiscal year 1993, work will continue on the development of the 3D quench propagation analysis code. This code simulates quench propagation in a system of multiple, inductively-coupled coils using low-temperature superconductors ( $\mathrm{NbTi}$ and $\mathrm{Nb}_{3} \mathrm{Sn}$ in liquid $\mathrm{He}$ ) and for the high-temperature superconductors using liquid $\mathrm{N}_{2}$.
As they have done in the past, researchers at MIT will gather information on actual magnet failures and make that information available to the fusion and magnet safety communities.

The Magnet Safety Research task will continue to collect failure rate information to provide the ITER team with guidance for the safe design and safety analysis of the magnet sets. This information will be incorporated into a magnet failure data base by the Fusion Safety Program. 


\section{References}

1. S. J. Piet, "Implications of Probahilistic Risk Assessment for Fusion Decision Making," Fusion Technology, 10, 1986, pp. 31-48.

2. L. C. Cadwallader and D. F. Holland, "Incorporating Reliability into the Design of Experimental Fusion Facilities," Proceedings of the 12th Symposium on Fusion Engineering, Monterey, California, October 12-16, 1987, IEEE Catalog Number 87CH2507-2, pp. 1262-1266.

3. L. C. Cadwallader, Magnet Operating Experience Review for Fusion Applications, EGG-FSP-9977, November 1991.

4. H. Becker, J. M. Tarrh, and P. G. Marston, "Failure of a Large Cryogenic MHD Magnet," Journal de Physique, 45, 1984, C1-603 to 606.

5. N. Mitchell, L. Bottura, and S. Chiocchio, Safety Analysis of the Superconducting Magnet System of a Next Generation Tokamak, N/R/3500/28/B, the NET Team, March 16, 1992.

6. W. Kramer, R. Meyder, S. Raff, K.-P. Jüngst, and H. Kronhardt, "Preliminary Safety Assessment of the NET Magnet System," KfK-5059, Kernforschungszentrum Karlsruhe, August 1992.

7. M. Huguet et al., "Present Status of Commissioning and Operation of JET," Fusion Technology 1984, 13th Symposium on Fusion Technology, Varese, Italy, September 24-28, 1984, pp. 91-103.

8. L. C. Cadwallader, "Identification and Selection of Initiating Events for Experimental Fusion Facilities," Proceedings of the 13th Symposium on Fusion Engineering, Knoxville, Tennessee, October 2-6, 1989, IEEE Catalog Number 89CH2820-9, pp. 1103-1107.

9. L. C. Cadwallader, "External Events Analysis for Experimental Fusion Facilities," Fusion Technology, 19, 1991, pp. 1349-1354.

10. L. C. Cadwallader, Cryogenic System Operating Experience Review for Fusion Applications, EGG-FSP-10048, January 1992.

11. R. J. Thome, Minutes of the Meeting on ITER Configuration at JET on May 1, 1992, Massachusetts Institute of Technology, May 10, 1992.

12. R. J. Thome, J. P. Freidberg, and A. Shajii, Safety and Protection for Large-Scale Magnet Systems-FY-92 Report, PFC/RR-93-1. 


\section{PLASMA SAFETY ISSUES}

\section{Researchers: B.J. Merrill, INEL; S.C. Jardin, PPPL}

Plasma off-normal events in tokamaks, such as plasma disruptions, plasma overpower transients, and impurity ingress accidents, can produce severe structural damage and potentially mobilize tritium, activated dust, and structural activation products. For example, "hard" plasma disruptions rapidly release the plasma magnetic and thermal energy, creating significant protective tile erosion, and induced structural forces. In addition, high loop voltages occur that can generate high energy runaway electrons. If the generated runaway current is large, these electrons could cause significant first wall and blanket damage when lost from the plasma.

Since the stored energy of tokamak plasma scales with major radius and plasma current, and since reliable methods for extrapolating disruptive rates to large tokamaks have not been developed, plasma off-normal events are proving to be crucial design and safety issues for next generation tokamaks. It is therefore important to have some calibrated disruption models to enable meaningful extrapolation to tokamak reactor parameters.

Another plasma safety-related issue is emergency plasma shutdown. Future tokamak divertors and first walls will experience significant heating. A loss-of-coolant accident in these structures will require very rapid plasma shutdown to ensure survival (for example, less than several seconds for the divertor). A shutdown scenario of this timescale that will not induce a "hard" plasma disruption has not yet been identified. In addition, experiments or detailed models do not exist to demonstrate the feasibility of presently conceived shutdown scenarios.
With these issues in mind, the focus of the plasma safety task is to develop and validate comprehensive models to ensure that proposed reactor designs can safely withstand off-normal plasma events. These models are being added to the Tokamak Simulation Code (TSC), ${ }^{1}$ a tokamak free-boundary plasma physics code under development at the Princeton Plasma Physics Laboratory (PPPL), with the resulting code being called DSTAR. ${ }^{2}$ In adopting this approach, we self-consistently deal with plasma disturbances by accounting for plasma motion, plasma/impurity transport, and induced structural eddy currents.

\section{Major Accomplishments}

Two major accomplishments were completed under this task during fiscal year 1992: the review of the International Thermonuclear Engineering Reactor (ITER) Conceptual Design Activity (CDA) disruption design guidelines, and the development of two approaches for modeling runaway electrons with the DSTAR code. The following subsections describe these accomplishments.

ITER CDA Disruption Guideline Review. As part of the ITER U.S. Home Team Safety and Environment task (SAE-3.2), the Fusion Safety Program reviewed the ITER CDA disruption design guidelines to determine if accident-induced disruptions were more severe than these guidelines allowed. We identified four accident-induced disruption scenarios of concern: (a) a failure of the burn control system resulting in a plasma thermal runaway, ending with a beta limit disruption, (b) a coolant ingress accident produced by a divertor/first wall coolant line rupture, injecting coolant at 
$\approx 20 \mathrm{~kg} / \mathrm{s}$ into the plasma, (c) foreign objects such as tiles and diagnostic probes falling into the plasma, and (d) density limit disruptions for a machine configuration that uses high $Z$ material, such as tungsten, as a plasma-facing component armor material.

Five primary recommendations resulted from this review ${ }^{3}$ :

1) Expand existing guidelines to include the anticipated number of disruptions proceeding from a given energy or current level over a specified disruption duration. This would avoid the requirement for conservative assumptions in licensing analyses (i.e., applying the maximum energy and current levels over the shortest disruption duration).

2) Increase the divertor peak design energy density for the thermal quench phase of a disruption from $24 \mathrm{MJ} / \mathrm{m}^{2}$ to $60 \mathrm{MJ} / \mathrm{m}^{2}$ to allow for plasma thermal runaway events, and to $120 \mathrm{MJ} / \mathrm{m}^{2}$ for single null configurations.

3) Modify the CDA current quench duration extrapolation method to account for the fact that the plasma in ITER will not contact the vacuum vessel during disruptions (this extrapolation method was based on data from tokamaks where the plasma did contact the vacuum vessel during disruptions).

4) Supplement the current quench duration guideline with a representative current decay history or a peak-to-average decay rate specification to allow for more accurate disruption simulations.

5) Support experimental and theoretical work to improve the understanding of the impact that impurities have on the duration of the plasma current quench.
This impact can then be factored into disruption design guidelines.

Runaway Electron Modeling. We have started developing a runaway electron capability for the DSTAR code. Two approaches are being examined. The first treats the runaway electrons as a fluid. Starting from the Relativistic Lagrangian ${ }^{4}$

$L=-m_{e} c^{2} \sqrt{1-\frac{V^{2}}{c^{2}}}-e \vec{V} \cdot \vec{A}-e \phi$

where

$$
\begin{aligned}
& \mathrm{m}_{\mathrm{c}}=\text { electron rest mass } \\
& \mathrm{c}=\text { speed of light } \\
& \mathrm{V}=\text { electron velocity } \\
& e=\text { electron charge } \\
& \mathrm{A}=\text { magnetic vector potential } \\
& \phi \quad=\text { electrostatic potential }
\end{aligned}
$$

and using Lagrange's Equation and the radiant reactive force proposed by Russo, ${ }^{5}$ we arrived at the following equation for the toroidal component of runaway electron momentum

$$
\frac{d}{d t}\left(\gamma m_{e} R V_{\phi}-e R A_{\phi}\right)=-\frac{R V_{\phi}}{V^{2}} P_{s y n c}
$$

where

$$
\begin{aligned}
\gamma & =\text { relativistic mass correction } \\
\mathrm{R}= & \text { major radius } \\
\mathrm{V}_{\phi}= & \text { toroidal velocity component } \\
\mathrm{A}_{\phi}= & \text { toroidal magnetic potential } \\
& \text { component } \\
\mathrm{P}_{\text {sync }}= & \text { synchrotron radiative power density. }
\end{aligned}
$$


This equation is solved at each $(R, z)$ point on the DSTAR magnetics grid. The quantity inside the time derivative is the canonical angular momentum. Canonical momentum is exactly conserved, in the absence of frictional losses, on drift surfaces, which may be labeled as

$\Psi .=\Psi+g V_{u} / \Omega$

where

$\downarrow$ = magnetic poloidal flux

$\mathrm{g}=$ magnetic toroidal field function

$\mathrm{V}_{n}=$ electron parallel velocity

$\Omega=$ toroidal electron cyclotron frequency.

These drift surfaces are used to define surface average runaway electron production rates as ${ }^{6}$

$$
\begin{aligned}
\dot{S}_{r e}= & K\left(Z_{e f f}\right)\left(\frac{E_{c}}{E}\right)^{3\left(Z_{s+1}\right)^{116}} n_{e} v\left(V_{\text {th }}\right) \\
& \times \exp \left\{-\frac{E_{c}}{4 E}-\left[\frac{\left(Z_{\text {eff }}+1\right) E_{c}}{E}\right]^{12}\right\}
\end{aligned}
$$

where

$$
\begin{aligned}
& \mathrm{Z}_{\mathrm{eff}} \quad=\text { plasma effective charge } \\
& \mathrm{K}\left(\mathrm{Z}_{\mathrm{eff}}\right)=\text { constant that depends on } \mathrm{Z}_{\mathrm{eff}} \\
& \mathrm{E}_{\mathrm{c}} \quad=\text { critical electric field } \\
& \mathrm{E} \quad=\text { applied electric field } \\
& \mathrm{n}_{\mathrm{e}} \quad=\text { plasma electron density } \\
& v\left(\mathrm{~V}_{\mathrm{th}}\right)=\text { coulomb collision frequency. }
\end{aligned}
$$

The time integration of these production terms gives runaway electron densities and current.

Figure 9 contains predicted plasma and runaway electron current for Tokamak Fusion Test Reactor (TFTR) disruptive shot 19964. Also contained in this figure is the measured plasma current. The current plateau after $4.096 \mathrm{~s}$ results from the runaway electrons carrying the majority of the plasma current beyond this time.

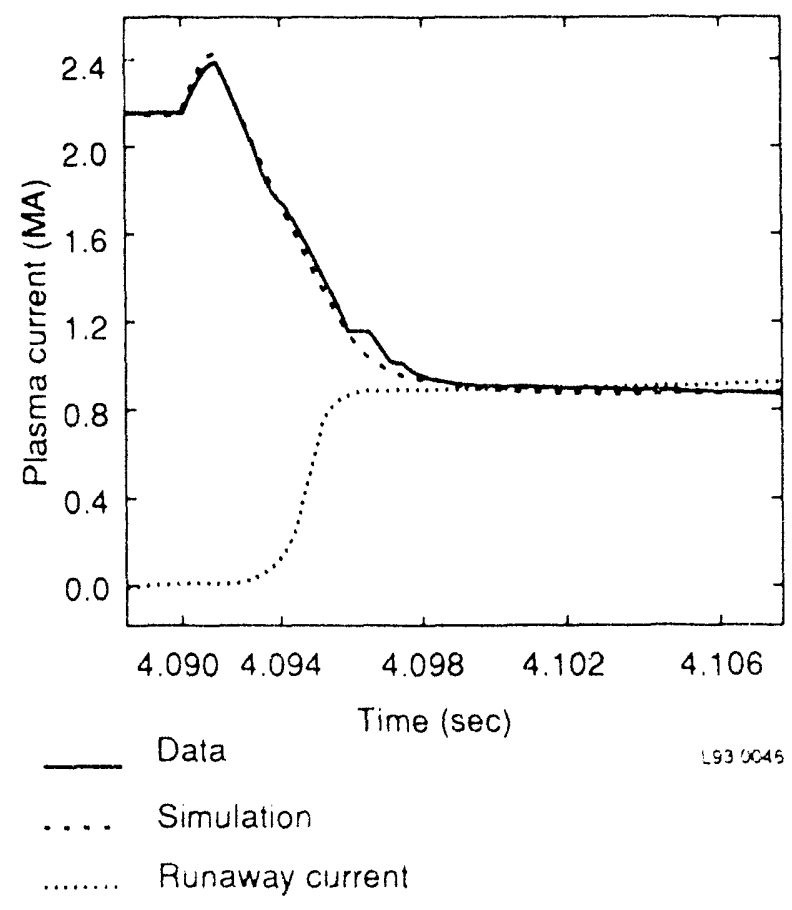

Figure 9. Predicted plasma and runaway electron current for TFTR disruptive shot 19964.

A second modeling approach is based on the direct integration of the electron drift velocity equation to give the time-dependent orbit of the runaway electron. Figure 10 contains the results of such an integration for an electron that accelerates from 0 to $200 \mathrm{MeV}$ in $5 \mu \mathrm{s}$, and remains at $200 \mathrm{MeV}$ for $25 \mathrm{~ms}$. The contours of this figure are drift surfaces for $200 \mathrm{McV}$ electrons. As expected, the electron moves radially outward during acceleration because of 


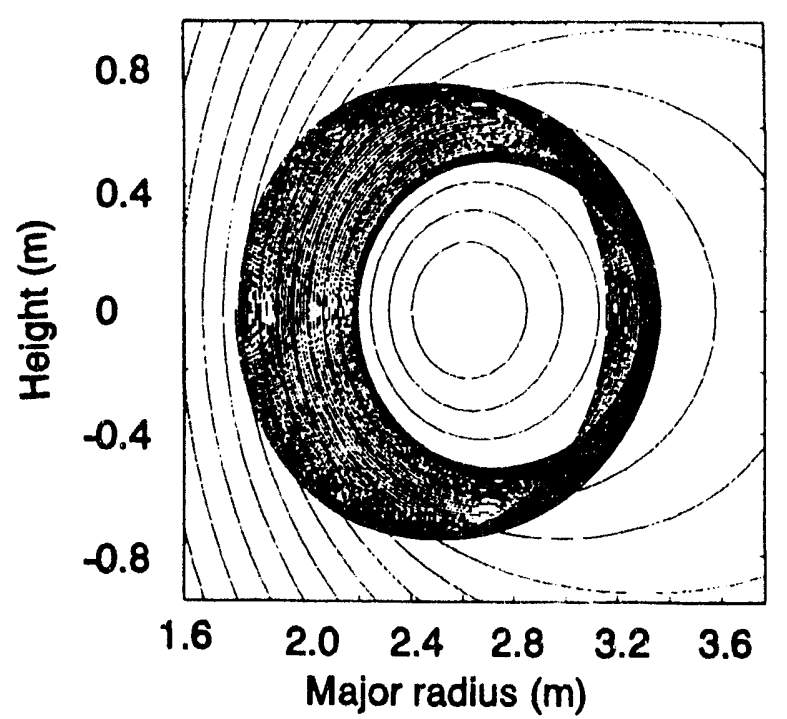

Figure 10. Runaway electron drift orbits.

the centrifugal force acting on the electron, and remains on a drift surface where canonical momentum is conserved once the acceleration stops. Combining this particle drift model with a particle in cell technique gives runaway electron densities and current in DSTAR.

\section{Future Activities}

Development of an impurity scrape-off-layer transport model for DSTAR will continue next fiscal year. This model will be applied to ITER to determine the feasibility of passive plasma shutdown scenarios by impurity gas injection.

Based on the performance and accuracy of the runaway electron models under development, a runaway electron model will be adopted for DSTAR in fiscal year 1993. In addition, DSTAR validation studies will continue with comparisons being made between predictions and disruption data from noncircular tokamaks such as D-III-D, PBX-M, or the Joint European Torus (JET). 


\section{References}

1. S. C. Jardin, N. Pomphrey, and J. Delucia, "Dynamic Modeling of Transport and Positional Control of Tokamaks," Journal of Computational Physics, 66, 1986, p. 481.

2. B. J. Merrill and S. C. Jardin, "DSTAR: A Comprehensive Tokamak Resistive Disruption Model for Vacuum Vessel Components," Fusion Engineering and Design, 5, 1987, pp. 235-249.

3. Letter from B. J. Merrill, Idaho National Engineering Laboratory, to J. N. Dogget, Lawrence Livermore National Laboratory, "Worst Case Accident-Induced Disruption Recommendations," (ITER/US/92/EN/SA-9), (available from EG\&G Idaho, Inc., P.O. Box 1625, Idaho Falls, Idaho, 83415-3523), September 29, 1992.

4. J. D. Jackson, Classical Electrodynamics, New York: Juın Wiley \& Sons, 1975, pg. 574.

5. A. J. Russo, "Effect of Ripple on Runaway Electrons in Tokamaks," Nuclear Fusion, 31, 1, 1991, pp. 117-126.

6. R. H. Cohen, "Runaway Electrons in an Impure Plasma," Physics of Fluids, 19, 1976, pg. 239. 


\section{RISK ASSESSMENT}

\section{Researchers: L. C. Cadwallader, A. S. Rood, and M. L. Abbott, INEL}

We use risk assessment both as a means to improve the safety of fusion designs and to develop a rational apprcach to safety assessment. The U.S. Department of Energy (DOE) also recognizes this dual role in DOE Order 5480.23, "Nuclear Safety Analysis Reports." We must further strengthen our knowledge of fusion component failure rate data values, and develop a regulatory quality radiological dose computer code.

Development of these fusion-specific probabilistic risk assessment (PRA) tools is important to support fusion safety in design and regulation. There are two major areas of PRA work that must be strengthened to make PRA easily applicable to fusion facilities: the component failure rate data base and fusion relevant radiological dose consequence computer codes. We report here on our activities in both of these areas.

\section{Major Accomplishments}

\section{Scaling Component Failure Rates.} Developing component failure rate information for design safety and regulatory use requires us to utilize data from other industries that are either longer-lived or more widely pursued. The industries with largest commonality with fusion are aerospace, particle accelerator, and nuclear fission. Since fusion experiments have historically been pulsed and will continue to be pulsed as pursuit of a steady-state machine continues, we have made an initial investigation of the likely variance in failure rates for pulsed and steady-state components, considering the source of the failure rate information.' Our approach to a data bank is depicted in Figure 11. In general, steady-state operations favor component reliability. Other data work was also performed to support the International Thermonuclear Experimental Reactor (ITER). This work includes surveys of magnet operating experiences, ${ }^{2}$ cryogenic system operating experiences, ${ }^{3}$ and a failure data analysis of a tritium glovebox system. ${ }^{4}$

Dose Consequence Computer Codes. In a cooperative effort with Dr. L. Miller and D. Chanin, the developers of the Melcor Accident Consequence Code System (MACCS), ${ }^{5}$ a fusion relevant version of MACCS is being generated at the Sandia National Laboratory in Albuquerque (SNLA). Dr. Miller has agreed to update the MACCS code with fusion relevant radionuclides in exchange for our updated food chain model. The former FUSEMOD ${ }^{6}$ food chain model was totally revised and is now calied COMIDA ${ }^{7}$ (this name is Spanish for food).

COMIDA : a dynamic food chain model that calculates radionuclide concentrations in food products following an acute fallout event. COMIDA gives seasonally-dependent radionuclide concentrations for five types of crops and an integrated concentration in milk, beef, poultry, and other animal products. Plant growth and senescence, tillage, foliar interception, weathering, resuspension, rainsplash, percolation, soil leaching, soil fixation, foliar absorption, and radioactive decay and ingrowth are modeled. The inventories of up to three radioactive progeny aiso are calculated. Timing of the accident impacts the radionuclide concentrations calculated in food products because COMIDA accounts for seasonal differences in plant biomass, plant growth rate, animal grazing and feeding practices, and crop harvest time. 
The addition of COMIDA to the MACCS code should enhance it, and the addition of fusion-relevant radionuclides to MACCS should make it a very versatile dose cote for particle accelerator, reprocessing, and tusion facilities. Unfortunately, MACCS toes not calculate tritium doses. SNLA and the Fusion Safety Program both endorse the UFOTRI computer code developed at Kemforschungszentrum Karlsruhe (KfK) for caiculating radiological doses from accidental tritium releases. ${ }^{8}$

\section{Future Activities}

We plan to continue Tritium System Test Assembly component isilure rate studies, focusing on the air detritiation system in fiscal year (FY) 1993. We also plan to study operating experiences from vacuum systems and remote handling systems in fusion and other high technology fields to set order-of-magnitude failure rates for components in these systems.

We will continue to work cooperatively with SNLA on the MACCS update. Plans for this work include a peer group test of the updated MACCS code in early FY 1993, and release of the code in mid FY 1993. Other longer term plans include investigation of combined cryogen (nitrogen or helium) and radionuclide releases to identify effects of ncgative plume rise while the cryogen warms.

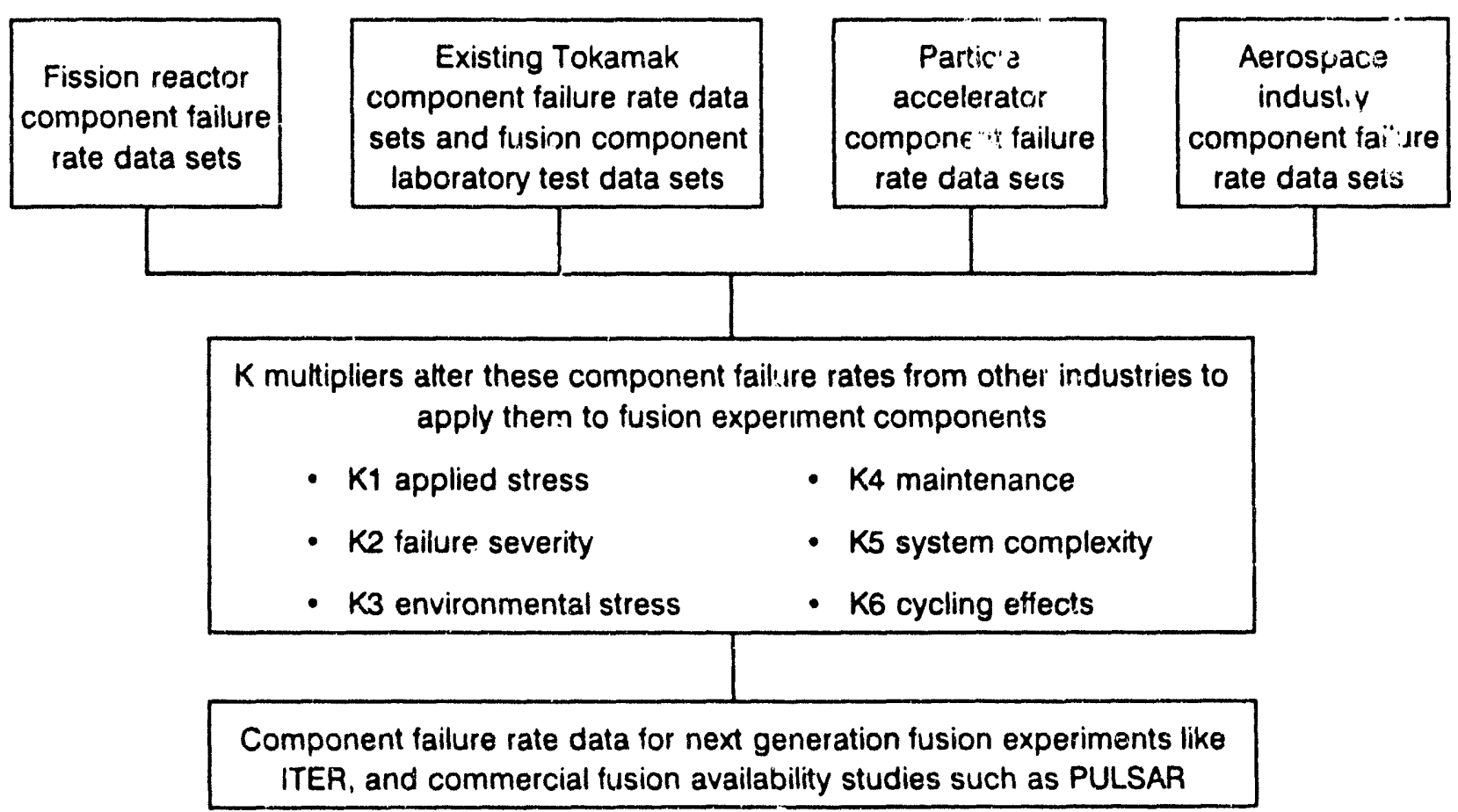

Figure 11. Collecting and applying failure rate data for fusion usage. 


\section{References}

1. L. C. Cadwallader, Investigation of Component Failure Rates for Pulsed Versus Steady State Tokamak Operation, EGG-FSP-10262, July 1992.

2. L. C. Cadwallader, Magnet Operating Experience Review for Fusion Applications, EGG-FSP-9977, November 1991.

3. L. C. Cadwallader, Cryogenic System Operating Experience Review for Fusion Applications, EGG-FSP-10048, January 1992.

4. L. C. Cadwallader and D. P. Sanchez, Secondary Containment System Component Failure Data Analysis from 1984 to 1991, EGG-FSP-10323, August 1992.

5. D. I. Chanin et al., MELCOR Accident Consequence Code System (MACCS) User's Guide, NUREG/CR-4691, SAND86-1562, February 1990.

6. M. L. Abbott and A. S. Rood, Concentration Factors for Fusion-Related Radionuclides Calculated Using the Food-Chain Model FUSEMOD, EGG-EST-9223, September 1990.

7. M. L. Abbott and A. S. Rood, COMIDA: A Radionuclide Food-Chain Model for Acute Fallout Deposition, EGG-GEO-10367, 1993.

8. W. Raskob, UFOTRI, Program for Assessing the Off-site Consequences from Accidental Tritium Releases, KfK-4605, July 1990. 


\section{ATHENA DEVELOPMENT}

\section{Researchers: K. E. Carlson, J. E. Tolli, A. S.-L. Shieh, and B. J. Merrill, INEL}

Fusion experiments, and eventually fusion reactors, will require several interacting coolant systems to remove heat from the first wall, blanket, limiter or divertor, and cryogenic superconducting magnets. Different cooling fluids will be used in each of the systems. These separate systems will be interconnected by heat exchangers, and can be affected by plasma or magnetic field configuration variations that cause the power being delivered to these cooling systems to change.

To understand and analyze the interactions among these cooling systems, the Idaho National Engineering Laboratory (INEL) is developing ATHENA, a transient analysis code, to allow simulation of both routine and accident conditions. This code will eventually provide an advanced best-estimate predictive capability for use in a wide spectrum of fusion reactor transient applications.

ATHENA is based on a nonequilibrium model for the two-phase fluid conservation equations, which are solved by a fast numerical scheme to permit economical calculations for cooling system transients. The objective of the ATHENA development effort is to produce a code that includes important first-order effects necessary for accurate prediction of system transicnts, but is sufficiently simple and cost effective to allow parametric or sensitivity studies.

The code includes many generic component models from which general systems can be modeled. The component models include pumps, valves, pipes, heat structures, reactor point kinetics, electric hesters, jet pumps, turbines, separators, and control system components. In addition, special process models are included for effects such as form losses, flow at abrupt area changes, branches, choked flow, magnetohydrodynamic (MHD) effects, solute tracking, and noncondensable gases.

The ATHENA code is based on the RELAP5/MOD3 code $^{2}$ and is being developed by modifying RELAP5 to include a range of fluids and new constitutive models. By adopting this approach, ATHENA benefits from extensive experience in modeling two-phase processes and light water reactor (LWR) systems, and from the validation experience with experimental fission reactor data. Additional experience has been gained through use of ATHENA by many research and development institutions in the U. S. and in several foreign countries.

\section{Major Accomplishments}

To be used in future licensing analysis for tokamak reactors, ATHENA will have to become a verified and validated (V\&V) computer code. This fiscal year, we concentrated our efforts on the $V \& V$ of ATHENA/MOD1. This code is a multi-fluids extension of the most recent version of the RELAP5/MOD3 code series. ${ }^{2}$

We conducted two validation studies. The first examined the accuracy of ATHENA to predict post-critical heat flux (post-CHF) heat transfer for liquid nitrogen $\left(\mathrm{LN}_{2}\right){ }^{3} \quad$ Post-CHF heat transfer is a heat transfer regime that occurs once the surface heat flux exceeds that which can physically be carried away hy liquid boiling. After this point, a vapor blanket develops between the surface and the liquid coolant in the cooling channel. 
To validate the ATHENA models for this heat transfer regime, we adopted data from an experiment performed by R. P. Forslund. ${ }^{4}$ Forslund's experiment introduced slightly subcooled $\mathrm{LN}_{2}$ into a $2.4-\mathrm{m}$ stainless steel pipe with an inside diameter of $9.2 \mathrm{~mm}$. The test section was electrically heated to produce heat fluxes of up to $78,800 \mathrm{~W} / \mathrm{m}^{2}$, and was instrumented axially with thermocouples every $0.1 \mathrm{~m}$.

Figure 12 contains some results from this study. Contained in this figure are predicted and measured surface temperatures versus axial location for three different surface heat fluxes. These results were obtained from ATHENA by enhancing the interphase (vapor to liquid) heat transfer by a factor of twelve. Adequate agreement was obtained with this enhancement factor, but additional model development needs be undertaken next fiscal year to determine why the interphase heat transfer model in ATHENA underpredicts this mode of energy exchange.

The second validation study dealt with the fusion-specific fluid property subroutines of ATHENA. ${ }^{5}$ These fluids are helium, nitrogen, lithium, and lithium-lead. The report from this study includes the equations used to derive the property tables of the ATHENA code, and compares the following predicted properties against measured data:

- Saturation pressure

- Specific volume

- Specific heat

- Specific internal energy

- Specific entropy

- Thermal expansion

- Isothermal compressibility

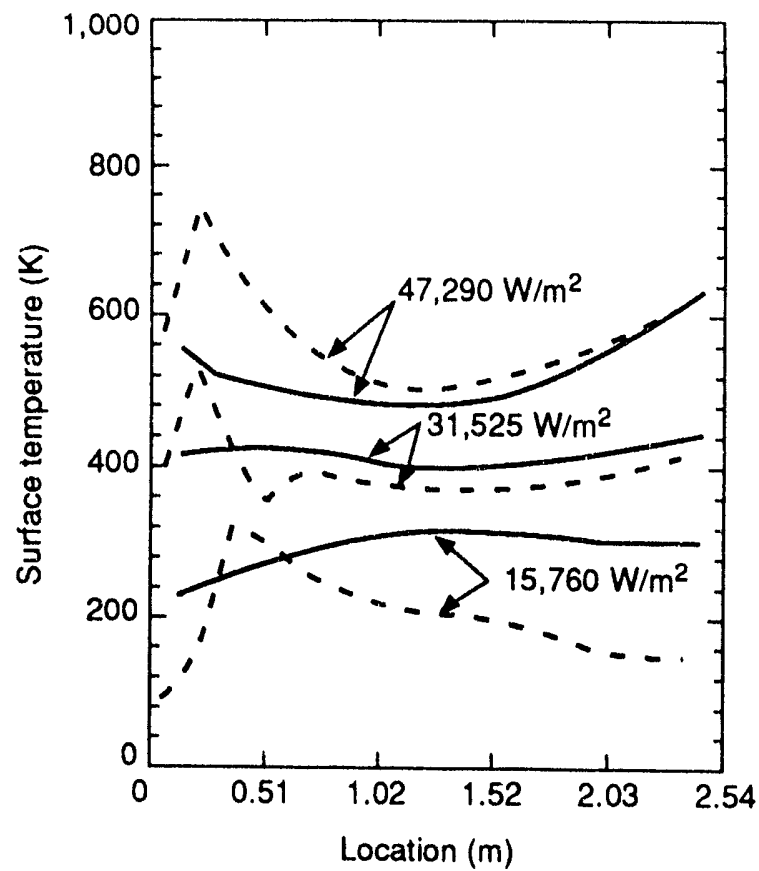

- Experimental data

L83 0045

- - ATHENA calculations

Figure 12. Comparison of ATHENA calculations using the Forslund correlation and interphase heat transfer with an enhancement factor of twelve.

- Surface tension

- Thermal conductivity

- Viscosity.

The agreement between predicted and measured values was within the uncertainty of the correlations used to generate the fluid property tables of ATHENA (i.e., typically much less than 10\%). However, predicted vapor properties for the liquid metals at low temperatures and pressures showed unacceptable deviations. We intend to correct these discrepancies in the future. 


\section{Future Activities}

During the upcoming fiscal year, we will add a steady-state MHD pressure drop model for circular and rectangular ducts to ATHENA. The predictive capabilities of the post-CHF heat transfer model will be corrected. A standard problem set assessment will be performed for ATHENA/MOD1. We will be contacting ATHENA users to inform them that a new version of ATHENA is ready for release.

The goal of future ATHENA user support will be to assist in the widest possible use of ATHENA by the fusion community. Design and safety analysis support will also be provided to the International Thermonuclear Engineering Reactor design study. 


\section{References}

1. K. E. Carlson, P. A. Roth, and V. H. Ransom, ATHENA Code Manual, Volumes 1 and 2, EGG-RTH-7397, September 1986.

2. K. E. Carlson et al., RELAP5/MOD3 Code Manual, Volumes 1-4, NUREG/CR-5535, EGG-2596, Draft, (available from EG\&G Idaho, Inc., P.O. Box 1625, Idaho Falls, Idaho 83415-2404), June 1990.

3. A. S.-L. Shieh, and K. E. Carlson, A Comparison of Boiling Correlations in ATHENA to Nitrogen Data, EGG-NE-10457, June 1992.

4. R. P. Forslund and W. M. Rohsenow, "Dispersed Flow Film Boiling," Journal of Heat Transfer, November 1968.

5. J. Tolli, Overview of Property Formulations for Helium, Nitrogen, Lithium, and Lithium-Lead in ATHENA/MOD1 with Comparison of Calculated Properties to Measured Properties, EGG-FSP-10245, April 1992. 


\title{
SAFETY AND ENVIRONMENTAL STUDIES FOR THE TOKAMAK PHYSICS EXPERIMENT
}

\author{
Researchers: L. C. Cadwallader, D. F. Holland, \\ and C. G. Motloch, INEL; M. A. McKenzie-Carter, SAIC; \\ J. C. Commander, Consultant
}

The Idaho National Engineering Laboratory Fusion Safety Program and subcontractors have been engaged in safety and environmental analyses to obtain regulatory approvals for the Tokamak Physics Experiment (TPX) design effort at the Princeton Plasma Physics Laboratory (PPPL). The TPX design is for a small superconducting tokamak, proposed after cancellation of the Burning Plasma Experiment in September 1991.

\section{Major Accomplishments}

An Action Description Memorandum (ADM) describing the TPX project was prepared, reviewed by PPPL, and delivered to the U.S. Department of Energy (DOE) Chicago Field Office at the end of June 1992. ${ }^{1}$ Another ADM was prepared describing the proposed decontamination and decommissioning (D\&D) of the Tokamak Fusion Test Reactor (TFTR) at Princeton. ${ }^{2}$ An ADM is a brief description of a proposed project intended to support DOE in determining the appropriate level of environmental documentation for the project.

In early October 1992, a letter from the DOE Princeton Area Office Manager stated that an environmental assessment (EA) was the appropriate level of initial documentation and that the TFTR D\&D task should be included in the EA. ${ }^{3}$ Inclusion of the TFTR D\&D project was requested to verify that no cumulative impacts of the two projects would be overlooked in separate analyses.

\section{Future Activities}

We have begun writing the combined EA for the TPX project. Based on our experience with the Burning Plasma Experiment EA, ${ }^{4}$ the new features of this design are the use of superconducting magnets, the use of water coolant in the titanium vacuum vessel, much longer pulse times, and different radiation shielding. These issues are being addressed. We also will support and assist in the TFTR D\&D Project Plan, the TFTR D\&D Project Management Plan, and updates of the TFTR D\&D cost estimates. The TPX/TFTR D\&D EA should be sent to DOE for review and comment in mid fiscal year 1993. DOE will review the EA and either issue a finding of no significant impact (FONSI) or else suggest preparing an environmental impact statement. DOE gave a verbal, preliminary FONSI on the BPX EA in September 1991; we anticipate similar findings for the TPX/TFTR D\&D EA. 


\section{References}

1. D. F. Holland, EG\&G Idaho, letter to J. Schmidt, Princeton Plasma Physics Laboratory, "TPX Action Description Memorandum," DFH-33-92, (available from EG\&G Idaho, Inc., P.O. Box 1625, Idaho Falls, Idaho, 83415-3523), June 17, 1992.

2. G. R. Walton, memo to distribution, "Subject: D\&D Action Description Memorandum," Princeton Plasma Physics Laboratory memo D\&D-00013-DDOC, (available from EG\&G Idaho, Inc., P.O. Box 1625, Idaho Falls, Idaho, 83415-3523), May 29, 1992.

3. M. D. Johnson, DOE Princeton Area Office Manager, letter to R. Davidson, Director of PPPL, "National Environmental Policy Act (NEPA) Determination for the Proposed Construction and Operation of the Tokamak Physics Experiment (TPX) at the Princeton Plasma Physics Laboratory (PPPL), Princeton, New Jersey," (available from EG\&G Idaho, Inc., P.O. Box 1625, Idaho Falls, Idaho, 83415-3523), October 8, 1992.

4. Draft Environmental Assessment, The Burning Plasma Experiment at the Princeton Plasma Physics Laboratory, DOE/EA-0522D, (available from EG\&G Idaho, Inc., P.O. Box 1625, Idaho Falls, Idaho, 83415-3523), September 1991. 


\title{
ARIES TOKAMAK REACTOR DESIGN STUDY
}

\author{
Researchers: J. Stephen Herring, T. J. Dolan, \\ and K. A. McCarthy, INEL; \\ G. J. Butterworth, Culham Laboratory
}

For the last four years, we have been participating in the ARIES tokamak design study, primarily working to ensure the safety of the resulting reactors. The ARIES program has been very important to the overall fusion program in demonstrating the potential safety and environmental attractiveness of commercial fusion reactors. That attractiveness will not be apparent in the International Thermonuclear Experimental Reactor (ITER), which must use present-day materials.

Table 4 presents a summary of the four ARIES designs. Clearly, the choices of fuel and materials have a major impact on the attractiveness of the design. All of the ARIES designs have been completed. ${ }^{1}$ Documentation of the ARIES-II and ARIES-IV designs will be completed in fiscal year (FY) 1993. Future work by the ARIES team will focus on pulsed tokamak operation and on a design for the demonstration reactor to follow ITER.

During FY 1992 we focused on the ARIES-II and ARIES-IV reactor studies. Both reactors are deuterium-tritium (D-T)-fueled, with ARIES-II using a vanadium structure and liquid lithium coolant, while ARIES-IV uses a silicon carbide structure and helium coolant.

\section{Major Accomplishments}

Safety and low environmental impact have been major emphases in all of the ARIES visions of tokamak reactors. Two ways of enhancing fusion reactor safety are to ensure adequate heat removal under all credible conditions and to reduce the inventory of radioactive materials.
The environmental impact of a fusion reactor can be reduced by avoiding the production of radioactive wastes. The ARIESII design ensures adequate cooling of the blanket by using the massive heat sink of a liquid lithium blanket. This design uses a vanadium structure that could be recycled, which would reduce the need for radioactive disposal. The ARIES-IV design uses silicon carbide as the structural material and lithium oxide as the breeder in order to reduce the induced radioactivity. Both ARIES-II and ARIES-IV will benefit from reduced inventories in the tritium handling system. In this report, we will highlight the work done on vanadium recycling ${ }^{2,3}$ and the reduced tritium pumping system.

Vanadium Recycling. Vanadium alloys with selected alloying elements can have low residual long-term radioactivity, which will permit their recycling, provided that impurity levels are kept very low. After irradiation and cooling, activated structural materials may either be recycled or consigned to permanent waste disposal. The choice will be based on costs, regulations, and political conditions.

The Fusion Safety Program investigated the need for recycling, vanadium production methods, purity requirements, purification techniques, and recycling procedures during FY 1992. Disposal of fusion reactor structure as low-level waste (LLW) could become difficult. For LLW to qualify as "Class C" (near-surface disposal) under 10 CFR 61 in the U.S., ${ }^{4}$ the calculated dose rate to an "intruder" up to 500 years in the future should be $<5 \mathrm{mSv} / \mathrm{yr}$. However, the specific activity limits (SAL) in 
Table 4. Comparison of the four ARIES designs.

\begin{tabular}{|c|c|c|c|c|}
\hline ARIES visions & I & II & III & IV \\
\hline \multicolumn{5}{|l|}{ Approach } \\
\hline Stability & First & Second & Second & Second \\
\hline Engineering & Aggressive & Near-term & Near-term & Aggressive \\
\hline Fuel & D-T & D-T & $\mathrm{D}-{ }^{3} \mathrm{He}$ & D-T \\
\hline Structure & SiC composite & Vanadium & Ferritic steel & SiC composite \\
\hline Coolant & $\mathrm{He}$ & $\mathrm{Li}$ & Organic coolant (OC) & $\mathrm{He}$ \\
\hline Breeder & $\mathrm{Li}_{2} \mathrm{ZrO}_{3}$ & $\mathbf{L i}$ & None & $\mathrm{Li}_{2} \mathrm{O}$ \\
\hline Advantages & $\begin{array}{l}\mathrm{SiC}, \mathrm{He} \\
\text { Low activation, } \\
\text { afterheat, } \\
\text { good Waste } \\
\text { Disposal Rating }\end{array}$ & $\begin{array}{l}\text { Low pressure, } \\
\text { massive coolant, } \\
\text { simple design, } \\
\text { V recycling }\end{array}$ & $\begin{array}{l}\text { Low } \mathrm{n} \text { flux, } \\
\text { long life, } \\
\text { most activation in massive } \\
\text { shield }\end{array}$ & $\begin{array}{l}\mathrm{SiC}, \mathrm{He}, \mathrm{Li}_{2} \mathrm{O} \\
\text { very low } \\
\text { activation, } \\
\text { afterheat }\end{array}$ \\
\hline Problems & $\begin{array}{l}\mathrm{Zr} \text { activation, } \\
\mathrm{W} \text { activation, } \\
\text { challenging } \\
\text { magnets and } \\
\text { structure }\end{array}$ & $\begin{array}{l}\text { Li fires, } \\
\text { no established } \\
\text { vanadium indus- } \\
\text { try }\end{array}$ & $\begin{array}{l}\text { Severe physics, } \\
\text { OC fires, } \\
\text { W activation, } \\
{ }^{3} \text { He mining, } \\
\text { excess tritium }\end{array}$ & $\begin{array}{l}\text { Chemical } \\
\text { compatibility? } \\
\text { May need } \\
\text { advanced } \\
\text { divertor }\end{array}$ \\
\hline Conclusions & $\begin{array}{l}\text { Attractive reac- } \\
\text { tor requires low } \\
\text { activation } \\
\text { materials, } \\
\text { isotopic tail- } \\
\text { oring reduced } \\
\text { activation } 14 \times\end{array}$ & $\begin{array}{l}\text { Simple design, } \\
\text { attractive safety } \\
\text { features }\end{array}$ & $\begin{array}{l}\text { Advanced fuels } \\
\rightarrow \text { low activation } \\
\text { - severe plasma conditions } \\
\text { Organic coolant } \\
\text { - energy source }\end{array}$ & $\begin{array}{l}\text { Attractive } \\
\text { safety } \\
\text { features, } \\
\text { low afterheat, } \\
{ }^{24} \mathrm{Na} \\
\text { production, } \\
\text { need for } \mathrm{Be} \\
\text { metal }\end{array}$ \\
\hline
\end{tabular}

10 CFR 61 for very long-lived radionuclides are not conservative in today's climate, and future, more conservative, SAL could require impurity levels too low to be practically obtainable. In that case, the fusion reactor structure could be classified as high-level waste.

Future laws may prohibit near-surface disposal of nuclides that do not decay to benign levels within 100 years. Although current LLW disposal costs at the U.S. Ecology site (Hanford) are $\$ 2,500$ per cubic meter, future costs could reach $\$ 35,000$ per cubic meter. Furthermore, the vanadium alloy is quite expensive to replace. Therefore, recycling is more desirable than shallow land disposal as a goal for fusion reactor materials. ${ }^{5}$

Vanadium alloys appear to be strong candidates for recycling for the following reasons: 
- Waste minimization. The amount of waste to be disposed in repositories would be greatly reduced by recycling, from $\approx 100$ metric tonnes per reactoryear to $<10 \mathrm{~kg}$ per reactor-year.

- Long-lived activation. Vanadium and some of its neighboring el nents in the periodic table exhibit relatively weak capture reactions with fusion neutrons and give rise to few long-lived activation products.

- Initial purification cost. Although vanadium is not a scarce or rare element, it is widely distributed in nature. It is, however, expensive in the finished metal form since its concentration at the ore stage, purification, and high temperature forming in a protective atmosphere are costly operations. The intrinsic value of the end-of-service structural material therefore favors its recovery and recycling in future reactors.

- Ease of repurification. The activation products should be readily removable in a high vacuum remelting operation. The waste products would have a much smaller volume than that of the reclaimed material, thus substantially reducing the volume of waste requiring geological disposal.

- Resource availability. To replace half the current electrical capacity of $750 \mathrm{GWe}$ in the U.S., about 375 fusion reactors of capacity $1 \mathrm{GWe}$ could be needed. If each reactor contained 400 metric tonnes (t) of vanadium with $200 \mathrm{t}$ of first wall/blanket replaced every four years, and the required cooling time were 40 years, then a commitment of $825 \mathrm{kt}$ would be needed. The current U.S. vanadium reserves are $185 \mathrm{kt}$, with an additional 2,400 kt "reserve base" recoverable at higher cost, and "resources" of
$30 \mathrm{Mt}$ available, though difficult to recover. After forty years, availability of the recycled alloy would lower the demand for new vanadium and help to prevent price escalation.

- Public acceptance. With the growing popularity of recycling programs, the feasibility of recycling fusion reactor structural materials could help fusion power earn public acceptance.

To reduce storage costs and new alloy purchases, recycling should be performed as early as feasible. For reuse in fusion reactors there are no statutory limitations on the allowable dose rate of recycled materials, though there are obvious advantages in being able to handle materials without excessively strict precautions.

- Electronic components that might be incorporated into remote handling limit the surface $\gamma$-dose rate. A tentative limit is $10 \mathrm{mG} / \mathrm{hr}(1 \mathrm{rad} / \mathrm{hr}){ }^{6}$ However, hardened electronic components can withstand total lifetime doses of 100 to $1,000 \mathrm{G}$ and absorbed doses can be reduced by shielding around cameras and sensors.

- For "hands-on" recycling, dose rates around $10 \mu \mathrm{Sv} / \mathrm{hr}(1 \mathrm{mrem} / \mathrm{h})$ would be needed, with only minimal radiological precautions.

Thorough purification of the constituent elements in vanadium alloys will be needed to remove troublesome impurities such as niobium, silver, molybdenum, and cobalt. Of the impurities considered, cobalt dominates the dose rate at medium cooling times, up to about $60 \mathrm{yr}$, through the relatively short-lived isotope ${ }^{60} \mathrm{Co}(5.27 \mathrm{yr})$. The other elements give rise to longer-lived radionuclides and are thus relatively more important at long cooling times (beyond $50 \mathrm{yr}$ ). 
Industry has developed sophisticated processes for purifying nickel-based superalloys such as the Nimonic series $(80 \mathrm{Ni}-20 \mathrm{Cr})$ and Hastelloy series (60Ni-15Cr-15Mo), and impurity levels of about 44 elements are routinely analyzed. ${ }^{7}$ The availability of ultrapure titanium and chromium stems from their use in the aerospace industry, which demands very tight compositional specifications. Pure titanium is also required for sputter ion targets.

Vanadium metal, on the other hand, has few applications, so there has been no industrial incentive to strive for higher purities. We can expect substantial improvements in the future.

Because all vanadium compounds are toxic, vanadium vapors must be contained during melting. Arc melting and electron-beam melting can be used to avoid sulfur contamination. Levitation melting has been accomplished using induction coils in a vacuum. Cerium is used as a scavenger during melting to remove oxygen, carbon, nitrogen, and sulfur. Vanadium oxidizes rapidly at high temperatures, and protective electroplates adhere poorly to it. ${ }^{8}$

Reduced Tritium Pumping System. The vacuum pumping system described here reduces tritium inventories in the vacuum pump and in the processing system. The reduced tritium pumping system has allowed the ARIES-II and -IV designs to have much smaller components than a traditional tritium handling system and to reduce the tritium inventory by a factor of two. Reducing the inventory in the vacuum pump is particularly important because this tritium is more vulnerable for release than inventories in the processing system. Tritium inventories are reduced in the processing system by direct recycle, returning tritium to the fueling system with minimal processing.

Direct recycle means bypassing the processing system that performs helium removal, impurity removal, and isotope separa- tion. Because of limits on impurity buildup in the plasma, the vacuum pumping system must remove helium and condensable impurities. Fortunately the temperatures of condensation are very different for hydrogen, helium, and condensable impurities so that separation can be done by a cryopump. Hydrogen isotope separation is more difficult but is required to remove protium and provide streams with enriched ratios of tritium. Protium removal and isotope enrichment cannot be done in the pump but will require external processing of a fraction of the flow.

The fraction of the flow that must be processed to remove protium depends on the allowed concentration in the plasma. In ITER, for example, helium impurity fractions of about 0.05 are tolerated. Therefore, the allowed fraction of protium in the plasma could be about 0.01 without adverse impacts significantly beyond that for helium buildup. Because of the low tritium burnup and because the particle confinement times for protium, deuterium, and tritium are reasonably close, the allowed protium fraction in the fuel is about the same as the allowed fraction in the $\mathrm{pl}:$ na. For the ITER Conceptual Design Activity (CDA), the protium source term was about 0.01 of the fueling rate. Therefore, the entire flow must be processed to keep the protium fraction in the plasma at 0.01 .

For direct recycle to be of benefit in reducing tritium inventories, the protium source term must therefore be reduced from the value used in the CDA. Protium comes from four sources: $D-D$ reactions, water leaks (since ARIES-II is not water-cooled, this is not an issue for ARIES-II), pellet injector gas, and outgassing from plasma-facing component materials and metal surfaces in the torus. The D-D source term is not significant since D-D reactions are at least two orders of magnitude less than D-T rates. The fraction of $D-T$ burned is only a few percent; therefore, the protium produced from $D-D$ reactions would be two orders of 
magnitude less. The source from the pellet injector can be eliminated by using centripetal injectors or by using deuterium as the propellant gas. The source term from the water leaks also could be reduced or eliminated by substituting helium coolant for water. Wall outgassing should be mimal after long operation. Based on these considerations, the ratio of the protium source term to the flow should be reducible by an order of magnitude. This would reduce the required processing fraction to 0.1 , allowing about $90 \%$ of the flow to be directly recycled.

If separation of condensable impurities and helium from the hydrogen isotopes can be done in the vacuum pump, external tritium flow and inventories can be reduced. These separations must be done without significantly increasing the inventory in the pump because tritium in the pump is at a higher risk than tritium in the external processing system.

Another related concern is maintenance of pumping systems that are exposed to neutrons and tokamak dust and are located at inaccessible places within the cryostat. Since helium, hydrogen, and condensable impurities have much different condensation temperatures, cryopumps have a good potential for performing these separations. Such a pumping system is proposed below. This system is ideally suited for pumping at the higher pressures and flows expected for gas divertors.

Two suggested improvements on cryopumps, if combined, would both reduce inventories in the pump and allow direct recycle. These ideas are the cryo-diffusion pump ${ }^{9}$ and the snail pump. $^{10}$ The snail pump is shown schematically in Figure 13.

The cryo-diffusion pump is a tube about $1 \mathrm{~m}$ in diameter and $5 \mathrm{~m}$ deep with an inlet portion at $77 \mathrm{~K}$ and a lower portion at $4 \mathrm{~K}$. The hydrogen isotopes will condense on the $4 \mathrm{~K}$ section and impurities such as water and methane will

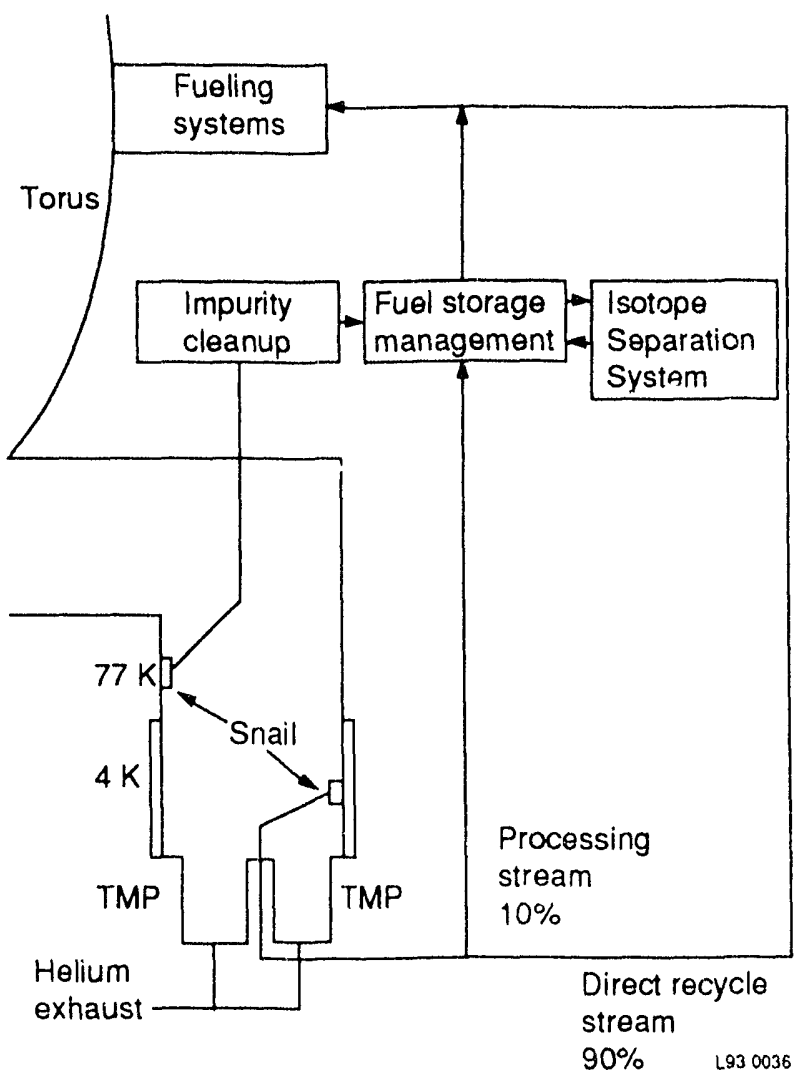

Figure 13. Snail pump schematic.

condense on the $77 \mathrm{~K}$ section. With this size and the hydrogen pressures expected during burn and dwell, the flow will be in the transition/viscous regime. As a result, the incoming $\mathrm{D}-\mathrm{T}$ will carry the helium along by viscous drag, resulting in sufficient compression for a turbomolecular pump to continuously remove it.

The frost formed in the cryopumps by the condensing gases can be removed by snails with moving heads that either scrape the frost off or remove it thermally. By adding two snails to this pump, the impurities and hydrogen can be separately and continuously removed.

\section{Future Activities}

The ARIES-II and ARIES-IV designs were developed during fiscal year 1992. Documentation of those designs will be completed during the first half of fiscal year 
1993. Following its completion, the ARIES team will assemble a number of "lessons learned" from the four ARIES visions. The team will then investigate the feasibility and desirability of a pulsed tokamak design.
We also will explore the logical role of a demonstration reactor that would be a near-commercial design following successful operation of ITER. 


\section{References}

1. J. S. Herring et al., ARIES-I Safety Design and Analysis, Draft, EGG-FSP-9434, 1991.

2. Farrokh Najmabadi et al., The ARIES-I Tokamak Reactor Study, Final Report, Volumes I and II, UCI_A-PPG-1323, 991.

3. Falrokh Najmabadi (ed.), The ARIES-III D-3He Tokamak Reactor Study, The Collection of Papers Presented at the IEEE 14th Symposium on Fusion Engineering, San Diego, California, October 1-3, 1991, UCLA-PPG-1386, December 1991.

4. United States Code of Federal Regulations, 10 CFR 61, January 1, 1992.

5. D. G. Doran, "LLW Near-Surface Disposal and LAM Criteria," Proceedings of the IEA Workshop on Low Activation Materials, Culham Laboratory, Oxford, England, April 8-12, 1991, Volume Ii.

6. E. T. Cheng, D. K. Sze, J. A. Sommers, and O. T. Farmer, III, "Materials Recycling Considerations for D-T Fusion Reactors," 10th Topical Meeting on the Technology of Fusion Energy, Boston, Massachusetts, July 7-12, 1992.

7. G. J. Butterworth, "High Purity Low Activation Steels for Fusion," Proceedings of the IEA Workshop on Low Activation Materials, Culham Laboratory, Oxford, England, April 8-12, 1991, Volume II.

8. W. D. Wilkinson, Fabrication of Refractory l.1etals, New York: Gordon and Breach, 1970.

9. J.L. Hemmerich, "The Cryogenic Diffusion Pump-An Advanced Design for Fusion Reactor Primary Pumping and Fuel Processing," 4th Topical Meeting on Tritium Technology, Albuquerque, New Mexico, September 29-October 4, 1991.

10. C.A. Foster, "High-Throughput Continuous Cryopump," Journal of Vacuum Science and Technology, 5, 4, July/August 1987. 


\section{INTERNATIONAL THERMONUCLEAR EXPERIMENTAL REACTOR PARTICIPATION}

\section{Researchers: S. J. Piet and Fusion Safety Program staff}

The Fusion Safety Program (FSP) leads the U.S. safety and environmental (SAE) effort for the International Thermonuclear Experimental $R \cdot$ ' stor (ITER), which will be a fusion engineering test reactor. ITER participants are the United States, the European Community, the Russian Federation, and Japan. The three-year Conceptual Design Activity (CDA) ended in late 1990 with a major safety report. ${ }^{1}$ The sixyear Engineering Design Activity (EDA) formally started in July 1992.

The U.S. has continued ITER safety and environmental activities between the end of the CDA and the time in the EDA when the new international Joint Central Team (JCT), becomes fuily functional (in 1993). Rather than continuing to analyze the CDA design point, current efforts focus on improving knowledge and resolving problems identified in the CDA. The corresponding technical accomplishments are discussed elsewhere in this report, in the appropriate technical sections.

S. J. Piet is formally the U.S. ITER team SAE research and development (R\&D) task area leader. He also serves informally as the U.S. ITER team SAE design task area leader. (All such design positions are not yet formalized.)

\section{Major Accomplishments}

The following subsections describe some of the major accomplishments of the ITER participation task for fiscal year 1992. Specific R\&D and design analysis tasks supporting ITER (regardless of funding source) are described in other sections of this annual report. In fact, most of the work discussed in this report supports ITER. This section only contains broad and policy accomplishments.

Implementing U.S. Consensus ITER Safety Approach. The U.S. continues to work to implement the stronger role for safety and environment as endorsed by the 1991 U.S. National Review of ITER ${ }^{2}$ :

- "Early integration of safety and environmental (S\&E) requirements with other engineering objectives will be necessary if the device is to demonstrate the potential advantages of fusion (e.g., considerations of S\&E should play a larger role in determining the choice of materials for plasma-facing components)."

- "The status and priority of safety and environmental (S\&E) concerns should be upgraded in the EDA phase of ITER."

- "We concur with the recommendations in the CDR [the CDA safety report ${ }^{1}$ ] concerning needed efforts in the EDA phase to reduce ITER accident risks and with the uncertainties in accident-risk assessment. Further work on passive means of assuring safety is particularly important."

Accordingly, safety and environment is now considered an equal part in the U.S. ITER Home Team structure, along with specific design areas like magnets and divertors. The U.S. safety task area leader has briefed numerous groups on ITER safety assessments, approach, and policy.

Safety objectives are now included among the technical mission statements advocated by 
the U.S. for the EDA. Awareness is growing that not only must ITER be safely designed, constructed, and built, but ITER tests must provide most of the data base for a passively safe demonstration power plant, DEMO. Examples of the necessary testing include the following:

- Test physics to show how DEMO can have steady-state operation (promoting lower component failure frequency) and low disruption frequency. Demonstrate passive plasma shutdown.

- Test advanced fuel cycle components and methods to improve the effective plasma tritium burn fraction to show how DEMO's tritium inventories and hazards will be lower than ITER's.

- Test advanced divertor, first wall, and blanket components to show that advanced nuclear technologies and low activation materials can be used in DEMO to reduce activation hazards.

\section{Building International Consensus on ITER}

Safety Approach. U.S. personnel are building the international consensus on ITER safety, starting from the CDA safety report.' Discussions at the ITER Safety and Environmental Workshop in October $1992^{3}$ showed a clear international consensus. Safety design improvements are needed to increase attractiveness and increase margins against regulatory requirements. Solutions should be as passive as possible and practical. Safety R\&D is needed to improve safety understanding and ultimately provide the data base for regulatory approvals. Safety goals and design criteria need to be established early in the EDA for lowest overall cost.

\section{Safety Assessment of CDA to EDA} Changes. Specific assessments and proposals for safety improvements are found in other sections of this annual report. Table 5 provides a summary of potential changes and impacts on safety performance.

Continuing vigilance of safety performance is vital, even early in the EDA. Fortunately, the new JCT appears to be considering the highest priority $\mathrm{CDA}$ safety suggestions to enhance the passive safety of ITER:

- Reduce use of carbon because of its high tritium inventory and high chemical reactivity

- Solve the tungsten activation hazard problem (for example, removing tungsten)

- Increase the effective tritium burn fraction (probably via immediate recycle of tritium exhaust into the plasma), thereby reducing tritium throughput to fuel cycle components and corresponding tritium inventories.

Development of an ITER EDA Safety and Environmental Research and Design Plan. The current international safety and environmental data base and calculational tools are insufficient for regulatory purposes. Thus, we must have an international safety and environment R\&D plan for ITER. S. J. Piet has updated his proposed international $R \& D$ plan for safety and environment. This was discussed at the international ITER Safety and Environmental Workshop in October 1992. ${ }^{3}$ All feedback to date has been positive.

Figure 14 shows the interactive nature of design and R\&D tasks during the EDA. Different types of $R \& D$ are required: basic safety phenomena, regulatory-quality data base, and safety performance of specific ITER components. The last area should be managed by the associated design team with safety participation. 
Table 5. Summary of potential ITER changes and impacts on safety performance.

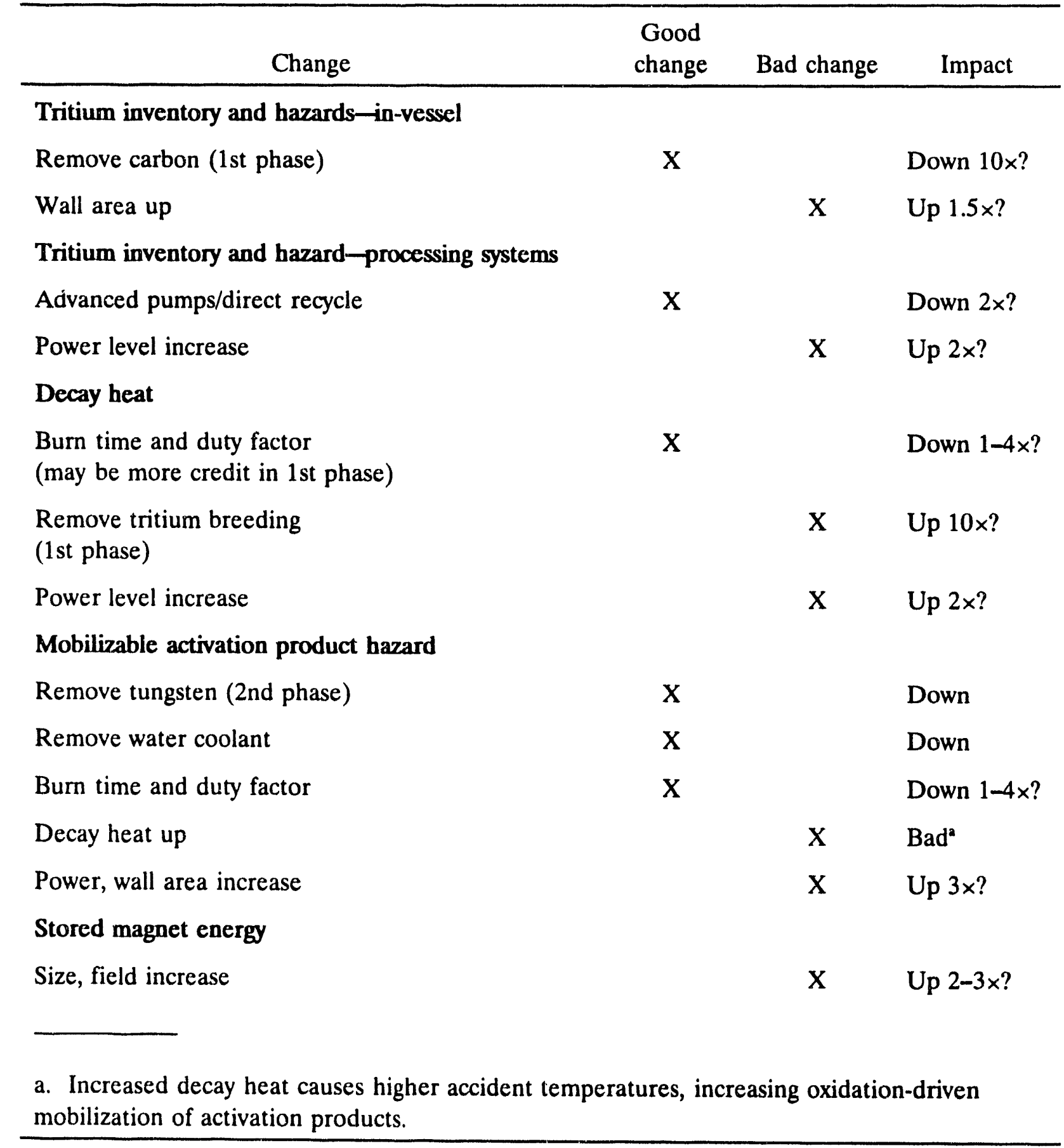

Initiation of the Process Leading to U.S. Regulatory Approval. We face complex siting and regulatory challenges, and the JCT will need effective safety and environmental review. FSP personnel are continuing to identify those U.S. Department of Energy (DOE) orders and U.S. Environmental Protection Agency (EPA) rules that apply to ITER. Clearly, the basic radiation protection criteria are appropriate. However, fission reactor requirements and guidelines are often not appropriate for a fusion facility like ITER. One helpful development is the beginning of a draft DOE order, 5480.FUS, for all U.S. DOE-Office of Fusion fusion test facilities. FSP and other U.S. ITER personnel are now involved with this 


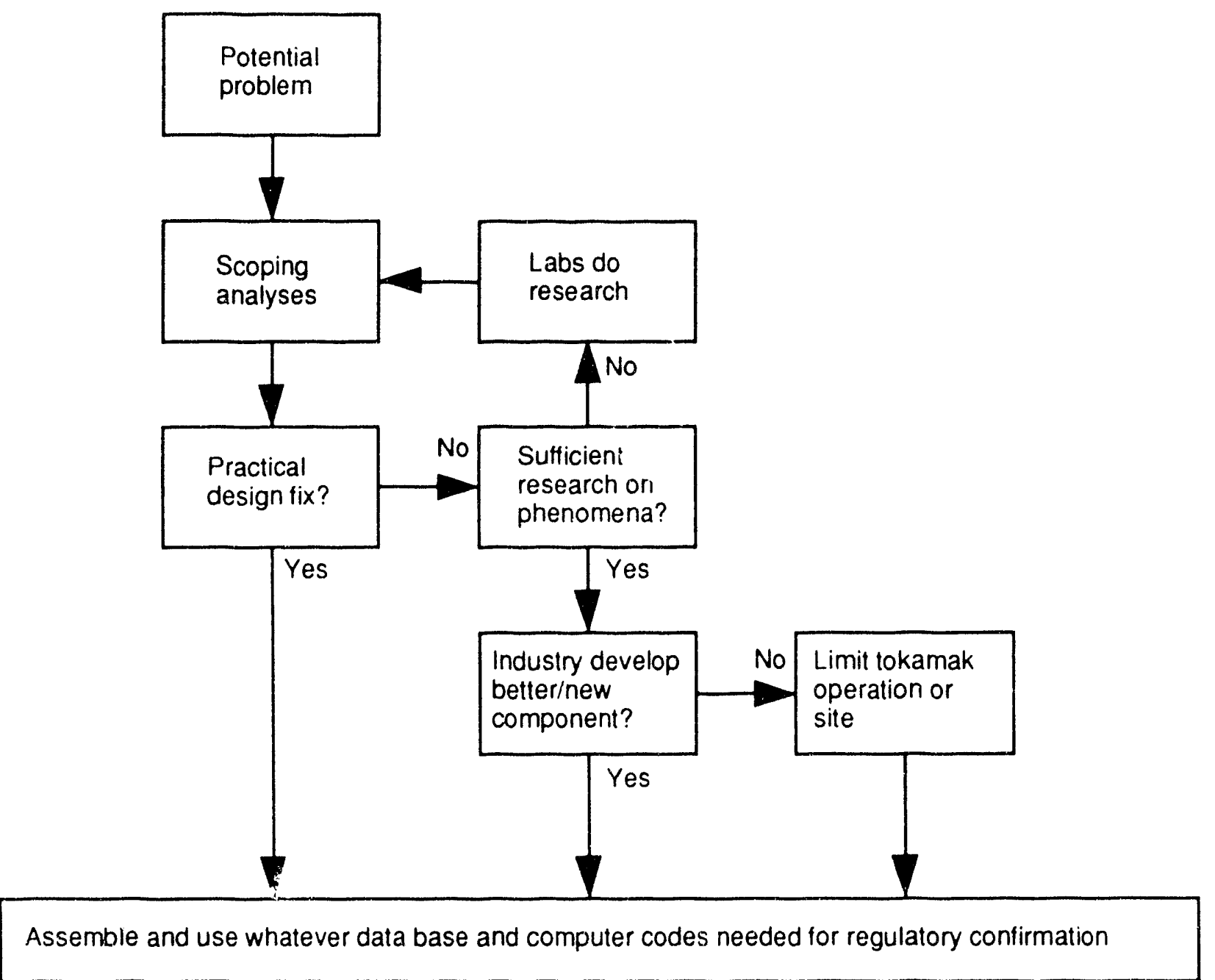

1900004

Figure 14. Cost-effective approach to solving fusion safety issues.

development in a steering and review capacity. Key ITER-related objectives include (a) showing how the graded approach to DOE Order compliance should work for fusion facilities, (b) avoiding fission requirements inappropriate for fusion, (c) establishing basic fusion safety requirements and goals, and (d) giving the logic for safety decisions. That logic proceeds from the complementary safety goals of (a) passively limit worst-case offsite doses to avoid being labelled as a "catastrophic

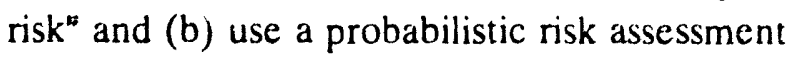
to show that public risk is below $0.1 \%$ of the existing background risk.
The underlying approach is to base design safety requirements as much as possible on a technically-driven logic, rather than automatically adopt existing prescriptive regulatory-driven requirements (see Figure 15). In the short-term, this implies more work in establishing design safety requirements. In the long-term, this approach reduces the cost of ITER, provides incentives to develop fusion technology to maximize its safety and environmental attractiveness, and builds positive precedents for fusion regulatory processes.

The ITER JCT cannot adopt the most conservative of each country's prescriptive 


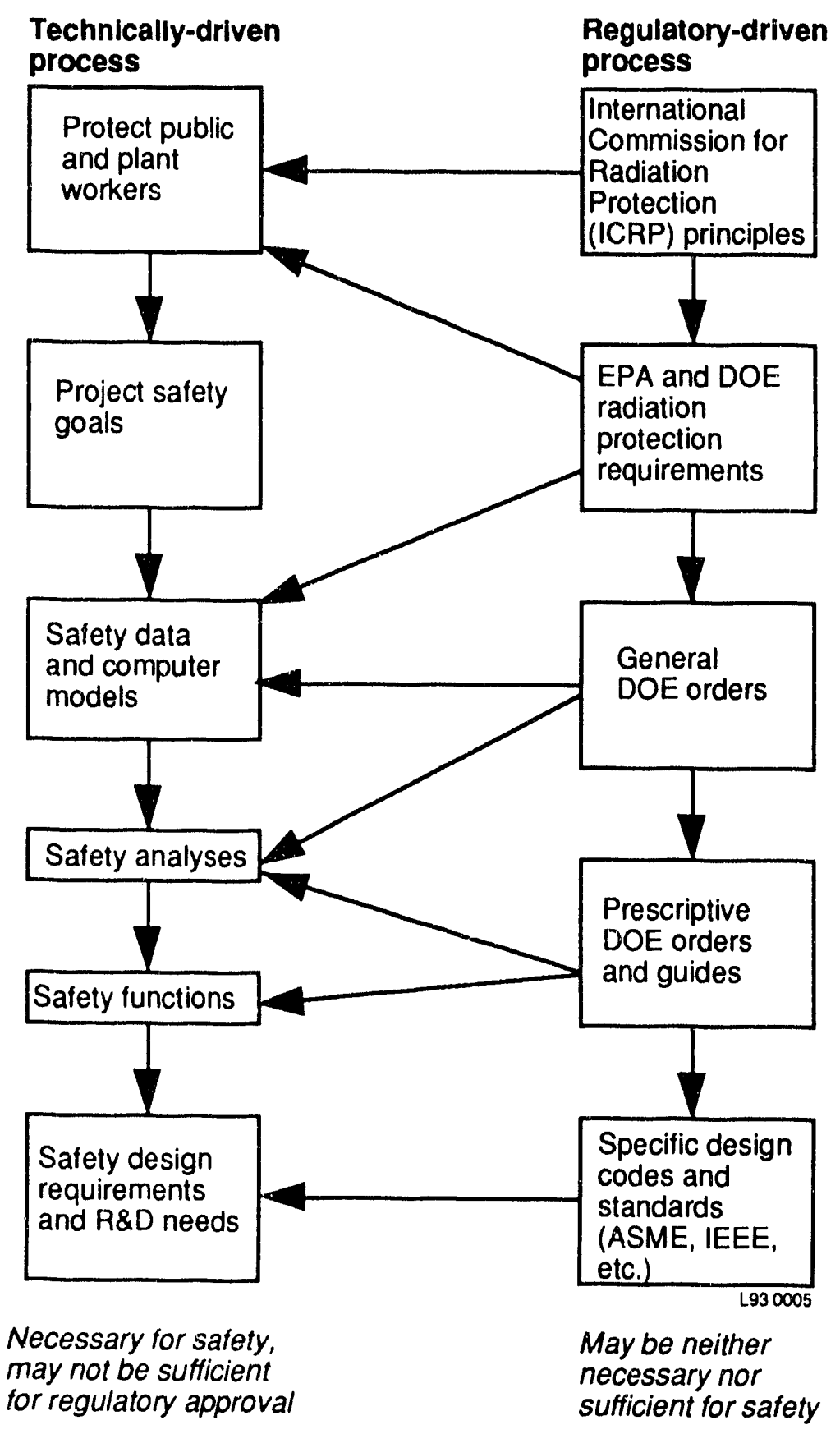

Figure 15. Distinction between technically-driven and regulatory-driven safety processes. 
safety regulations. Instead, we must use a technically-driven safety logic, building on international principles of radiation protection.

\section{Future Activities}

1993 will complete the transition from U.S.defined tasks to JCT-defined tasks as the JCT staff is assembled and becomes fully operational. FSP safety expertise will be an integral part of the effort. Experience shows that safety and environmental performance is maximized and achieved at least cost when considered early in the design process. Therefore, the FSP intends to actively encourage safety considerations in early design decisions. 


\section{References}

1. J. Raeder and S. J. Piet (eds.), ITER Safety Analyses, ITER Documentation Series, No. 36, International Atomic Energy Agency, Vienna, 1991.

2. D. E. Baldwin, chair, U.S. National Review of the Intermational Thermonuclear Experimental Reactor (ITER) Conceptual Design Acivity, March 1991.

3. "ITER Safety and Environmental Workshop Meeting Summary," ITER Safety and Environmental Workshop, ITER San Diego Co-Center, October 12-16, 1992. 


\section{Appendix A}

\section{Abstracts or Summaries of Fusion Safety Program Publications}




\section{Appendix A}

\section{Abstracts or Summaries of Fusion Safety Program Publications}

\section{Tritium Safety}

\author{
"Deuterium Transport and Trapping In \\ Polycrystalline Tungsten" \\ R. A. Anderl, D. F. Holland, G. R. Longhurst, \\ R. J. Pawelko, C. L. Trybus, and \\ C. H. Sellers, Fusion Technology, 21, March \\ 1992, pp. 745-751.
}

Deuterium permeation studies for polycrystalline tungsten foil have been conducted to provide data for estimating tritium transport and trapping in tungsten-clad divertors proposed for advanced fusion-reactor concepts. Based on a detailed transmission electron microscopy microstructural characterization of the specimen material and on analyses of permeation data measured at temperatures ranging from 610 to $823 \mathrm{~K}$ for unannealed and annealed tungsten foil ( $25 \mu \mathrm{m}$ thick), we note the following key results: (1) deuterium transport in tungsten foil is dominated by extensive trapping that varies inversely with prior anneal temperatures of the foil material, (2) the reduction in the trapped fraction correlates with a corresponding elimination of a high density of dislocations in cell-wall structures introduced during the foil fabrication process, (3) trapping behavior in these foils can be modeled using trap energies between 1.3 and $1.5 \mathrm{eV}$ and trap densities ranging from $1 \times 10^{-5}$ to $7 \times 10^{-5}$ atom fraction.
"Hydrogen Transport Behavlor of Beryllium"

R. A. Anderl, M. R. Hankins, G. R. Longhurst, R. J. Pawelko, and R. G. Macaulay-Newcombe, 10th International Conference on Plasma Surface Interactions in Controlled Fusion Devices, Monterey, California, March 30-April 3, 1992.

Beryllium is being evaluated for use as a plasma-facing material in the International Thermonuclear Experimental Reactor. One concern in the evaluation is the retention and permeation of tritium implanted into the plasma-facing surface. We performed laboratory-scale studies to investigate mechanisms that influence hydrogen transport and retention in beryllium foil specimens of rolled powder metallurgy product and rolled ingot cast beryllium. Specimen characterization was accomplished using scanning electron microscopy, Auger electron spectroscopy, and Rutherford backscattering techniques. Hydrogen transport was investigated using ionbeam permeation experiments and nuclear reaction analysis. Results indicate that trapping plays a significant role in permeation, reemission, and retention, and that surface processes at both upstream and downstream surfaces are also important. 


\section{TMAP4 User's Manual}

G. R. Longhurst, D. F. Holland, J. L. Jones, and B. J. Merrill, EGG-FSP-10315, June 12, 1992.

The Tritium Migration Analysis Program, Version 4 (TMAP4) has been developed by the Fusion Safety Program at the Idaho National Engineering Laboratory as a safety analysis code, mainly to analyze tritium retention and loss in fusion reactor structures and systems during normal operation and accident conditions TMAP4 incorporates onedimensional thermal- and mass-diffusive transport and trapping calculations through structures and zero dimensional fluid transport between enclosures and across the interface between enclosures and structures. A key feature is the ability to input problem definition parameters as constants, interpolation tables, or FORTRAN equations. The code is specifically intended for use under a DOS operating system on PC-type mini-computers, but it has also been run successfully on workstations and mainframe computer systems. Use of the equation-input feature requires access to a FORTRAN-77 compiler and a linker program.
Verification and Validation of TMAP4 G. R. Longhurst, S. L. Harms, E. S. Marwil, and B. G. Miller, EGG-FSP-10347, July 8, 1992.

The Tritium Migration Analysis Program MOD1/CY04 (TMAP4) was written to be used in analyzing experiments and for safety calculations that involve the injection, solution, diffusion, trapping, release, and other related processes experienced by hydrogen isotopes in materials. Because of the desire to make it suitable for analyzing safety issues, it is important that TMAP4 be certified (verified and validated) at Quality Assurance Level A. This report documents the work done to achieve that certification. The process includes ensuring that the developed code meets the software requirements specified in the software quality assurance plan, verifying that the code functions in accordance with the written description and that it is self-consistent and internally correct, and validating that its computed results are in agreement with experimental data and/or known analytical solutions. Quality Level A certification for TMAP4 is specifically for implementation on an IBM PS/2 Model 70 operating under DOS 5.0. Certification for any other environment will require demonstration that all of the verification and validation tests documented here give the same results in the new environment. 


\section{Beryllium Safety}

Beryllium Technology Workshop, Cleanwater Beach, Florida, November 20, 1991

G. R. Longhurst, EGG-FSP-10017, December 1991.

In response to the continuing interest in beryllium for applications in fusion reactors, and as a followup to a similar workshop held September 11, 1989 at the Idaho National Engineering Laboratory, I and a number of the participants thought it would be worthwhile to hold a second workshop. The opportunity of holding it as a satellite meeting to the Fifth International Conference on Fusion Reactor Materials (ICFRM5) seemed too good to miss. With the approval of the organizing committee of ICFRM5, I solicited prepared remarks from a number of researchers in the field, and the workshop came into being.

The objectives of the workshop were to (a) bring researchers, developers, designers, and managers together, (b) get the "flavor" of work in progress on beryllium at the various institutions, (c) identify the areas where additional effort is most needed, and (d) communicate the results of these discussions to participants and others with financial or technical resources to pursue the tasks identified. The first three objectives were very satisfactorily met at the workshop. This summary, together with its attachments, is the primary means of achieving the fourth objective.
"Mechanical Properties of Irradiated Berylllum"

J. M. Beeston, G. R. Longhurst,

R. S. Wallace, and S. P. Abeln, Journal of

Nuclear Materials, 195, 1992, pp. 102-108.

Beryllium is planned for use as a neutron multiplier in the tritium breeding blanket of the International Thermonuclear Experimental Reactor (ITER). After fabricating samples of beryllium at densities varying from 80 to $100 \%$ of the theoretical density, we conducted a series of experiments to measure the effect of neutron irradiation on mechanical properties, especially strength and ductility. Samples were irradiated in the Advanced Test Reactor to a neutron fluence of $2.6 \times 10^{25} \mathrm{n} / \mathrm{m}^{2}(\mathrm{E}>1 \mathrm{MeV})$ at an irradiation temperature of $75^{\circ} \mathrm{C}$. These samples were subsequently compression tested at room temperature, and the results were compared with similar tests on unirradiated specimens. We found that the irradiation increased the strength by approximately four times and reduced the ductility to approximately one fourth. Failure was generally ductile, but the $80 \%$ dense irradiated samples failed in brittle fracture with significant generation of fine particles and release of small quantities of tritium. 


\section{Activation Product Chemical Reactivity, Volatility, and Transport}

\section{Tungsten Alloy Oxidation Behavior in Air and Steam}

G. R. Smolik, EGG-FSP-10166, March 1992.

This report presents oxidation rates derived from posttest evaluations of a tungsten alloy initially tested at the INEL in air and steam between 600 and $1200^{\circ} \mathrm{C}$. Oxidation behavior of pure tungsten in air and environments containing water vapor is initially reviewed. The oxidation rates that we have found for the alloy in air and steam, expressed as recession rates $(\mathrm{mm} / \mathrm{s})$, are then compared with rates reported in the literature for pure tungsten. We also have used weight changes and mass balances involved in the oxidation and volatilization processes to predict oxidation reactions and estimate remnant oxide products and quantities of hydrogen formed.

Relationships for the oxidation of the tungsten alloy in air and steam, and also hydrogen generation in steam, are given based on data extracted both from our tests and from the literature. These are the relationships recommended for fusion safety analyses based upon the current available information. Finally, a comparison of hydrogen production rates shows that the three primary plasma-facing component (PFC) materials ranked in increasing order are graphite, tungsten, and beryllium. Each of these materials, however, has other safety or performance features that impact PFC selection.

\section{Reaction of Porous Beryllium in Steam}

G. R. Smolik, B. J. Merrill, and

R. S. Wallace, EGG-FSP-10346, July 1992.

This report presents the findings of some additional investigations into the reaction of beryllium of approximately $88 \%$ theoretical density with steam. An earlier investigation had shown this material to be extremely reactive compared to dense beryllium. Inductively heated samples developed self-sustaining reactions because of the exothermic heat of reaction at temperatures between 600 and $700^{\circ} \mathrm{C}$. These initial tests did not completely explain the mechanisms causing this behavior. The onset of thermal instability appeared to have a temperature dependent incubation period and some dependence upon specimen geometry. Additional tests have clarified this behavior. We have also obtained measurements of emissivity and permeability. This information will be helpful in the future in modeling reactor accident scenarios. The high effective surface area of porous beryllium also has allowed reaction rates to be obtained at temperatures as low as $400^{\circ} \mathrm{C}$. The information for porous beryllium was then used to extend relationships for the reaction rates of dense beryllium in steam to these lower temperatures. 


\section{Oxidation and Volatilization of a Niobium Alloy}

G. R. Smolik, and K. A. McCarthy, EGG-FSP-10341, July 1992.

This report presents the findings from a preliminary investigation into oxidation and volatilization characteristics of a niobium alloy. Niobium is a candidate alloy for use in plasmafacing components (PFCs) in experimental fusion reactors like the International Thermonuclear Experimental Reactor. An experimental alloy was tailored to simulate small changes in chemistry that could result from transmutations from irradiation. The alloy was exposed in air and steam between 800 and $1200^{\circ} \mathrm{C}$. Volatilized products and hydrogen were collected and measured. Posttest examinations also were performed on the samples to determine the amount of material loss during the exposures. The obtained measurements of volatilization flux $\left(\mathrm{g} / \mathrm{m}^{2}-\mathrm{s}\right)$, hydrogen generation rates $\left(\mathrm{L} / \mathrm{m}^{2}-\mathrm{s}\right)$, and recession rates $(\mathrm{mm} / \mathrm{s})$ are data that can be used for safety analyses and material performance to predict consequences that may result from an accident involving the ingress of air or steam into the plasma chamber of a fusion reactor.

In our volatility tests, only molybdenum and niobium were found at release levels above the detection limit. Although molybdenum is present at only $0.12 \mathrm{wt} \%$, the quantities of this element volatilized in air are nearly comparable to the quantities of niobium released. The niobium release in stcam is only three to four times higher than that of molybdenum in steam.

The hydrogen production of the niobium alloy is compared with other PFC materials that we have tested - specifically, beryllium, graphite, and a tungsten alloy. At high temperatures, the hydrogen production rate of the niobium alloy is among the lowest of these materials, significantly lower than beryllium. To understand what this means in an accident situation, modeling is necessary to predict temperatures, and therefore total hydrogen production. The Idaho National Engineering Laboratory is currently doing this modeling.

The maximum dose mobilized for niobium and copper alloys are compared using copper data from previous tests at the Idaho National Engineering Laboratory because copper and niobium are candidates for divertor substrate material. We found that the maximum mobilized dose for niobium is generally around an order of magnitude lower than that for copper. Molybdenum is known to be highly volatile and our experiments confirmed this with high mass release of molybdenum relative to molybdenum weight percent in the niobium alloy we tested. Based on this and the dose hazard of molybdenum, we expect that miolybdenum, another candidate divertor substrate material, would show a higher maximum dose mobilized than either niobium or copper. 


\section{Exploratory Study of Burn Time, Duty Factor, and Fluence on ITER Activation Hazards}

S. J. Piet, EGG-FSP-10396, August 1992.

The safety analyses for the Conceptual Design Activity (CDA) of the International Thermonuclear Experimental Reactor (ITER) were based on the simplifying assumption that the activation of materials occurs continuously. Since the analyses showed a significant hazard, it is appropriate to examine how much hazard reduction might occur if this conservative assumption were relaxed. This report explores how much reduction might be gained by conjidering noncontinuous operation (i.e., by considering plasma burn time, duty factor, and integrated fluence). Other factors impacting activation hazards-material choice, flux, and size-are not considered here.

The analysis combines analytical expressions with detailed activation calculations performed by $\mathrm{H}$. Attaya (Argonne National Laboratory) during the ITER CDA in 1989 and 1990. Attaya's activation calculations generally assumed $100 \%$ duty factor (i.e., continuous irradiation). Pulsed operation allows some decay of isotopes between pulses. Reduction factors are defined as the ratio of the continuous activation hazard to the discontinuous hazard as a func'.on of burn time, duty factor, and total integrated fluence, and consequence measure. I studied five cases: austenitic steel, tungsten, and copper as first wall/side wall materials, and tungsten and niobium as diverter materials. These analyses assume $1.0 \mathrm{MW} / \mathrm{m}^{2}$ and $800 \mathrm{~m}^{2}$ area for first wall and $0.4 \mathrm{MW} / \mathrm{m}^{2}$ and $200 \mathrm{~m}^{2}$ for divertor; the reduction factors are not sensitive to these values.

Several issues exist when quantifying activation hazards, including dose from mobilized activation products, decay heat, and waste disposal. I performed all dose calculations consistent with the CDA. The two major mechanisms for mobilizing activation products are tokamak erosion dust and volatility in high temperature air and steam transients. The contribution of isotopes to total mobilized hazard is stoichiometric for dust but varies for air/steam volatility by temperature, gas, and alloy composition. Thus, we must consider which chemical elements' isotopes dominate particular hazards for each material. The two major consequence measures are specific early public dose $(\mathrm{mSv} / \mathrm{kg})$ and specific activity $\left(\mathrm{Ci} / \mathrm{cm}^{3}\right)$. For dose $(\mathrm{mSv} / \mathrm{kg})$, I identified which elements' isotopes dominate either tokamak dust or air/steam volatility.

One key parameter is the length of test campaigns, pulses linked together for some test: especially technology tests. For present purposes, a high duty factor campaign of pulses is effectivcly a single longer pulse. For example, a 2-week near-continuous ( $>90 \%$ ?) test campaign is effectively one pulse. The effective burn time is defined as the larger of the actual burn time or the duration of nearcontinuous test campaign.

For safety hazards, the most important parameters are effective burn time and duty factor; lower fluence gains little since shorterlived isotopes dominate. (Lower fluence does reduce buildup of long-lived isotopes for waste disposal, bui the volume and qualitative problems for ITER do not change.) Considering effective burn times (test campaigns) of 1-14 days and 20-30\% duty factors, the reduction factors for specific dose vary from 1.2 to 4.4 . For individual elements, the reduction factor goes as high as 14 .

If the ITER mission is reduced to only physics, then the effective burn time, fluence, and duty factor would presumably be lowered. Then the reduction factors for specific dose vary from 4.5 to 7.1 , increasing for some individual elements. 
Probabilistic risk reduction would combine these consequence factors with frequency reduction, (duty factor) ${ }^{-1}$, for that portion of total risk arising from tokamak operation instead of shutdown periods and maintenance. These reduction factors would be offset by increases in size and neutron flux.

To take credit for these factors in formal ITER safety assessments, detailed activation calculations would be required. The approximations here are sufficient to indicate the magnitude of the effect, but not sufficient for formal, quantitative safety assessments. Also, the maximum allowable operational parameters (burn time, duty factor, integrated fluence) would have to be established and made part of the "safety basis" regulatory case.

Finally, note that this report does not include the impact of any increases in size, wall loading, or total fusion power as are being currently discussed within the ITER community. Those changes would increase activation inventories. 


\section{Liquid Metal Chemical Reactions}

\section{Lquid Metal/Water Interactions in a Shock-Tube Geometry}

G. Vukovic, UWRSR 71, August 1991.

Our project is part of the safety studies concerned with the use of liquid $\mathrm{Li}_{17} \mathrm{~Pb}_{83}$ as a reactor blanket and tritium breeder. The purpose of this study is to investigate liquid metal/water interactions in general, and particularly to characterize the chemical kinetics of the liquid $\mathrm{Li}_{17} \mathrm{~Pb}_{83} / \mathrm{H}_{2} \mathrm{O}$ interaction through a series of small scale shock-tube experiments, and to develop a model to analyze the experimental results. In these experiments, a water column (driven by argon at high pressure) forcibly impacts a pool of liquid $\mathrm{Li}_{17} \mathrm{~Pb}_{83}$ in the lower portion of the stainless-steel shock tube. The driving pressure and initial $\mathrm{H}_{2} \mathrm{O}$ and $\mathrm{Li}_{17} \mathrm{~Pb}_{83}$ temperatures are the parameters of the experiments.

The physical, chemical, and thermal properties of $\mathrm{Li}$ and $\mathrm{Li}_{17} \mathrm{~Pb}_{83}$ are reviewed. In addition, the fuel/coolant interaction and small scale shock-tube experiments are reviewed. Previous experimental work of relevance to this proposal is presented. Research goals are stated, and the experimental apparatus (mechanical design, auxiliary equipment, measurement and data acquisition systems) is described. The experimental procedure and proposed test matrix are presented. Results of scoping tests performed on the (largely completed) shock-tube are presented.

\section{"Lithlum Alloy Chemical Reactlvity With Reactor Materlals: Current State of Knowledge"}

M. L. Corradini and D. W. Jeppson, Fusion

Engineering and Design, 14, 1991, pp. 273-288.

Experimental work and supporting analysis have been conducted by Westinghouse Hanford Company and the University of Wisconsin on lithium-lead alloy chemical reactivity. This work is in support of the U.S. Department of Energy Fusion Safety Program through EG\&G Idaho, Inc. These studies involve experiments with lithium-lead $\left(\mathrm{Li}_{17} \mathrm{~Pb}_{83}\right)$ and its interactions with air, nitrogen, carbon dioxide, concrete, steam, and water. The work at Westinghouse Hanford has been done to characterize potential safety concerns associated with the use of this alloy as a breeding and/or coolant material in fusion reactors. These activities primarily involve large and small scale integral experiments. The work at Wisconsin has focused on lithium alloy/water interactions and is concerned with the chemical kinetics in small scale separate effects tests. In addition, this work has been complemented by larger scale more prototypic tests and associated analyses at the Joint Research Center-Ispra. This paper discusses recent results and the status of our knowledge. 


\section{Magnet Safety Research}

"Magnet Initiating Events for ITER Risk Assessment"

L. C. Cadwallader, 17th Symposium on

Fusion Technology, Rome, Italy, September 14-18, 1992.

Events resulting from fusion magnet faults, or events outside of the magnets that can seriously affect the magnet sets, are identified from operating experience reviews of medical, accelerator, and fusion magnets. These initiating events also have been given preliminary quantification applicable to the International Thermonuclear Experimental Reactor design. 


\section{Risk Assessment}

Investigation of Component Failure Rates for Pulsed Versus Steady State Tokamak Operation

L. C. Cadwallader, EGG-FSP-10262, July 1992.

This report presents component failure rate data sources applicable to magnetic fusion systems, and defines multiplicative factors to adjust these data for specific use on magnetic fusion experiment designs. The multipliers address both long pulse and steady-state tokamak operation. Thermal fatigue and radiation damage are among the leading reasons for large multiplier values in pulsed operation applications. Field failure rate values for graphite protective tiles are presented, and beryllium tile failure rates in laboratory testing also are given. All of these data can be used for reliability studies, safety analyses, design tradeoff studies, and risk assessments.

\section{Magnet Operating Experience Review for Fusion Applications}

L. C. Cadwallader, EGG-FSP-9977, November 1991.

This report presents a review of magnet operating experiences for normal-conducting and superconducting magnets from fusion, particle accelerator, medical technology, and magnetohydrodynamics research areas. Safety relevant magnet operating experiences are presented to provide feedback on field performance of existing designs and to point out the operational safety concerns. Quantitative estimates of magnet component failure rates and accident event frequencies also are presented, based on field experience and performance of similar components in other industries. 


\section{Cryogenic System Operating Experience Review for Fusion Applications}

L. C. Cadwallader, EGG-FSP-10048, January 1992.

This report presents a review of cryogenic system operating experiences from particle accelerator, fusion experiment, space research, and other applications. Safety relevant operating experiences and accident information are discussed. Quantitative order-of-magnitude estimates of cryogenic component failure rates and accident initiating event frequencies are presented for use in risk assessment, reliability, and availability studies. Safety concerns with cryogenic systems are discussed, including ozone formation, effects of spills, and modeling spill behavior. This information should be useful to fusion system designers and safety analysts, such as the team working on the International Thermonuclear Experimental Reactor.
Secondary Containment System Component Failure Data Analysis from 1984 to 1991

L. C. Cadwallader and D. P. Sanchez, INEL and LANL, EGG-FSP-10323, August 1992.

This report gives the failure rates for the major tritium containing glovebox systems that compose the Secondary Containment System at the Tritium Systems Test Assembly, which is a fusion research and technology facility at Los Alamos National Laboratory. The component failure reports, numbers of components, and operating times or demands are all given in this report. Sample calculations of the binomial demand failure rates and Poisson hourly frilure rates for these components form a solid data point based on actual operating experience, where there is very little published information. The eight years of nearly continuous Secondary Containment System operations should result in steady-state failure rate values. These data should be useful for future fusion reactor design work and safety assessment tasks. 
COMIDA: A Radionuclide Food-Chain Model for Acute Fallout Deposition

M. L. Abbott and A. S. Rood, EGG-GEO-10367, 1993.

A new dynamic food-chain model, "COMIDA," has been developed to estimate radionuclide concentrations in agricultural food products following an acute fallout event. COMIDA estimates yearly harvest concentrations for five human crop types ( $\mathrm{Bq} \mathrm{kg}{ }^{-1}$-crop per $\mathrm{Bq} \mathrm{m}^{-2}$-deposited) and integrated concentrations for 4 animal products ( $\mathrm{Bq} \mathrm{d} \mathrm{kg}{ }^{-1}$-animal product per $\mathrm{Bq} \mathrm{m} \mathrm{m}^{-2}$ ) for a unit deposition that occurs on any user-specified day of the year. COMIDA is structurally similar to the PATHWAY model and includes the same seasonal transport processes and discrete events for soil and vegetation compartments. Animal product assimilation is modeled using simpler equilibrium models. The inventories for up to three radioactive progeny are also calculated in each of the environmental compartments.

Benchmark results between COMIDA and PATHWAY for monthly fallout events show very similar seasonal agreement for ${ }^{131} \mathrm{I}$ and ${ }^{137} \mathrm{Cs}$ integrated concentrations in milk and ${ }^{137} \mathrm{Cs}$ integrated concentrations in meat. Benchmark results between COMIDA and six international steady-state models show good agreement for deposition events that occur during the middle of the growing season but significantly lower estimates by COMIDA before and after the growing season. For deposition events that occur just before harvest, COMIDA predicts significantly higher $(3 \times)$ integrated concentrations for leafy vegetables. COMIDA uses a fourth order Runge-Kutta numerical algorithm with variable time step and may be operated on a personal computer with a DOS operating system. Input is through two, free format ASCII files: one with site and scenario specific data and one with nuclide specific data. COMIDA will be implemented in the new version of the U.S. Nuclear Regulatory Commission's MELCOR Accident Consequence Code System (MACCS) for evaluation of accidental releases from nuclear power plants. 


\section{ATHENA Development}

\section{A Comparison of Boiling Correlations in ATHENA to Nitrogen Data \\ A. S.-L. Shieh and K. E. Carlson, EGG-NE-10457, June 1992.}

The application of the ATHENA code to an experiment using cryogenic nitrogen is presented. The calculated results from ATHENA are compared to the experimental data from the Forslund experiment. In the Forslund comparison, two sets of calculated results are available for presentation. The first comparison being calculated uses the DougallRohsenow correlation, while the second comparison is calculated using the ForslundRohsenow correlation.
Overview of Property Formulations for Helium, Nitrogen, Lithium, and LithiumLead in ATHENA/MOD1 with Comparison of Calculated Properties to Measured Properties

J. Tolli, EGG-FSP-10245, April 1992.

Formulations for the thermodynamic and transport properties of the fluids used by the ATHENA/MOD1 computer program for fusion safety research have been obtained from various sources, including published and empirical curvefitted data. The sources and/nr formulations are presented herein. Comparison plots of ATHENA calculated thermodynamic properties and transport properties with measured data are included as part of the verification and validation effort for the ATHENA fusion fluids. 


\section{Safety and Environmental Studies for the Tokamak Physics Experiment}

\author{
"Decommissioning Plan for the \\ Tokamak Fusion Test Reactor," \\ G. R. Walton and J. C. Commander, 10th \\ Topical Meeting on the Technology of Fusion \\ Energy, Boston, Massachusetts, June 7-12, \\ 1992.
}

The Tokamak Fusion Test Reactor (TFTR) Preliminary Decontamination and Decommissioning (D\&D) Plan was developed to provide a framework for estimating the costs and schedule for implementing a final D\&D plan. This work will be used in evaluating the future use of the TFTR Test Cell. D\&D planning and estimates were generated for two cases of plasma operations for TFTR. The first scenario is for continued operation in deuterium-deuterium (D-D) plasmas and subsequent decommissioning. This scenario would require D\&D to a TFTR that is slightly activated and contaminated but still with a capability for "hands-on" D\&D work. The second scenario calls for deuterium-tritium (D-T) plasma operations. In this scenario, TFTR becomes highly activated and contaminated with tritium. This operational scenario will result in a TFTR that will require $D \& D$ involving remote handling. The end result in either scenario would provide a test cell that is available for future use. This paper will discuss the D\&D objectives, management, safety and technical plans, and critical assumptions made in order to develop cost and schedule estimates.

\author{
Preliminary Decontamination \& \\ Decommissioning Plan for the \\ Tokamak Fusion Test Reactor, \\ Princeton Plasma Physics Laboratory, D\&D \\ 00012, DDOC, August 1992.
}

The Tokamak Fusion Test Reactor (TFTR) is scheduled to complete its end-of-life deuterium-tritium (D-T) experiments in September 1994. Thereafter, according to U.S. Department of Energy Order 5820.2A, "Radioactive Waste Management; Chapter V, Decommissioning of Radioactively Contaminated Facilities," the facility is required to be decontaminated and decommissioned. These decontamination and decommissioning (D\&D) activities will be the final phase of TFTR operations. The objectives of this preliminary plan are to develop a plan for TFTR D\&D that would utilize decommissioning technology available from nuclear fission, consider D\&D options available, select the $D \& D$ options that provide earliest availability of TFTR facilities, and develop costs and schedules for the D\&D options. D\&D options include: (1) mothballing (with later D\&D after components cool down), (2) in-place entombment, and (3) dismantling and removal of radioactive components. Only the third option provides for early availability for the TFTR test cell. Option 3 consists of two scenarios: one based on deuterium-deuterium experiments, the other based on deuteriumtritium experiments. This document describes Option 3 and its sub-options. 
"Safety in the ARIES-III D- ${ }^{3} \mathrm{He}$

Tokamak Reactor Design"

J. Stephen Herring and T. J. Dolan, 14th

IEEE/NPSS Symposium on Fusion

Engineering, San Diego, California,

September 30-October 3, 1991.

The ARIES-III reactor study is an extensive examination of the viability of a $\mathrm{D}^{3} \mathrm{He}$-fueled commercial tokamak power reactor. Because neutrons are produced only through side reactions $\left(D+D \rightarrow{ }^{3} \mathrm{He}+\mathrm{n}\right.$ and $\mathrm{D}+\mathrm{D} \rightarrow \mathrm{T}+\mathrm{p}$ followed by $\left.\mathrm{D}+\mathrm{T} \rightarrow{ }^{4} \mathrm{He}+n\right)$, the reactor has the significant advantages of reduced activation of the first wall and shield, low afterheat, and Class A or $\mathrm{C}$ low level waste disposal. Since no tritium is required for operation, no lithiumcontaining breeding blanket is necessary. A ferritic steel shield behind the first wall protects the magnets from gamma and neutron heating and from radiation damage.

The ARIES-III reactor uses an organic coolant to cool the first wall, shield, and divertor. The organic coolant has a low vapor pressure at the operating temperature required for good thermal efficiency. Radiation damage requires processing the coolant to remove and crack radiolytic prodicis that would otherwise foul cooling surfaces. The cracking process produces waste, which must be disposed of through incineration or burial. We estimated the offsite doses from incineration at five candidate locations.

The plasma confinement requirements for a D- ${ }^{3} \mathrm{He}$ reactor are much more challenging than those for a D-T reactor. Thus, the demands on the divertor are more severe, particularly during a disruption. We explored the potential for isotopically tailoring the 4-mm tungsten layer on the divertor in order to reduce the offsite doses should a tungsten aerosol be released from the reactor after an accident.

We also modeled a loss-of-coolant accident in which the organic coolant was burning in order to estimate the amount of radionuclides released from the first wall. Because the maximum temperature is low, $\angle 600^{\circ} \mathrm{C}$, release fractions are small. We analyzed the disposition of the $20 \mathrm{~g} /$ day of tritium that is produced by D-D reactions and removed by the vacuum pumps. For our reference design, the tritium will be burned in the plasma. These results re-emphasize the need for low activation materials and advanced divertor designs, even in reactors using advanced fuels. 

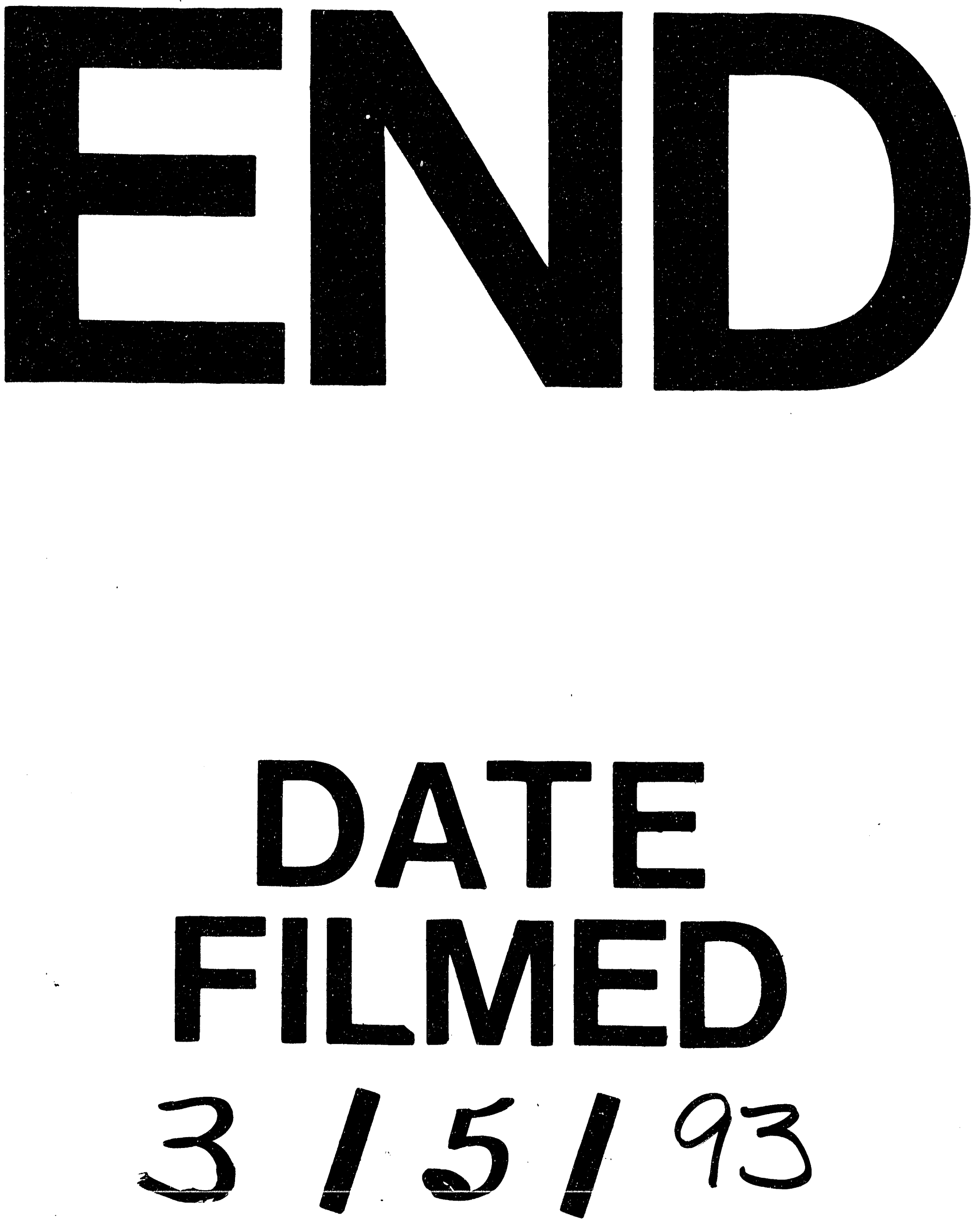
